\title{
UN ESTUDIO SOBRE LA TRANSFERENCIA DE TECNOLOGÍA EN LA INDUSTRIA MEXICANA DEL VESTIDO
}

\author{
Alfonso Mercado García, \\ antonio Juárez Cano y Jesús Aristy Melo \\ El Colegio de México
}

\section{INTRODUCCIÓN}

EN ESTE TRABAJO' se presentan los resultados de una investigación efectuada en México de marzo de 1978 a marzo de 1979, en el marco de un proyecto sobre los vínculos tecnológicos entre los sectores formal e informal en la industria manufacturera, auspiciado por la Oficina Internacional del Trabajo y dirigido por Susumo Watanabe. El proyecto contó con la participación de varios centros de investigación de América Latina, Asia y África.

Los principales objetivos de la investigación en México fueron: a) determinar y examinar la magnitud, forma y problemas de la transferencia de tecnología y habilidades del sector formal (local o extranjero) al informal y su difusión en el último (cómo y qué tanto se diseminan en su interior la tecnología y las habilidades transferidas), en una rama específica en cuyos establecimientos el sector informal tenga una participación elevada. Una de estas ramas es la fabricación de ropa; $b$ ) explicar las causas del éxito o el fracaso de varias formas de transferencia y difusión de tecnología y habilidades; $c$ ) sugerir una forma de estimular una transferencia exitosa de tecnología, de tal manera que pueda ayudar, en última instancia, a elevar el nivel económico y tecnológico de los establecimientos informales.

Para lograr tales objetivos se emprendió una investigación con base en información censal y de una encuesta. Los datos del censo permitieron analizar el patrón de desarrollo de la industrial local de la ropa, así como determinar y explorar la magnitud y evolución del sector informal en la rama referida. La encuesta ayudó a determinar los diversos tipos de transferencia de tecnología y habilidades, el contenido, los medios, así como la forma de transferencia y difusión de información técnica y del uso de trabajo con experiencia. La encuesta se dividió en dos partes. Una comprendió maquiladoras de exportación en la frontera norte de México (Mexi- 
cali) y la otra, productores locales orientados al mercado interno. El tamaño de la primera fue de seis empresas y el de la segunda fue de 25 establecimientos. Si bien estos tamaños son pequeños (representan el 7\% y el $0.3 \%$ del respectivo universo), se buscó una diversidad de casos para lograr un perfil aproximado de la realidad. En el cuadro 9 se aprecian las diversas características de las empresas cubiertas en la encuesta de 25 fábricas locales.

Este estudio puede ser útil desde el punto de vista académico y para la política económica y tecnológica local. En el primer sentido, se han planteado en la literatura sobre tecnología y desarrollo económico hipótesis de comportamiento sobre la transferencia internacional de tecnología y algunas sobre adaptaciones a la maquinaria y al proceso importados por países subdesarrollados. Pero no se ha analizado el fenómeno en conjunto, desde la importación hasta el desarrollo y difusión de tecnología propia o ajustes a la ajena. Por otro lado, la formulación de la política económica local requiere de clarificar el comportamiento tecnológico en lo específico para diagnosticar y analizar soluciones a problemas concretos. Este trabajo puede contribuir a tales fines.

En el texto se utilizan varios conceptos claves que es preciso definir. La tecnología de la ropa es el conjunto de conocimientos y habilidades sobre el diseño, el corte, la costura, el acabado y el empaque sistemático de ropa para su comercialización. También se incluyen otros elementos como es la información para la determinación del lay-out, los estudios de preinversión, el conocimiento para el mantenimiento de las máquinas y para el control de calidad de las prendas. La ropa se refiere a un grupo de prendas de vestir hechas de tela no de punto. Las prendas de punto se manufacturan generalmente con el uso de equipo textil y en tales establecimientos, por lo cual se consideran dentro de la industria textil. El sector informal de la ropa es el compuesto por los talleres de confección que emplean mano de obra sin salario (en pagos a destajo). No tienen acceso a los mercados organizados de sus productos, de insumos (máquinas, materia prima y trabajo) y financiero. Por lo general no disponen de un establecimiento dedicado exclusivamente a tareas manufactureras. El establecimiento informal de la ropa es típicamente una maquiladora muy pequeña (con menos de cinco personas ocupadas) ubicada en un lugar de una vivienda y a cargo de una extrabajadora-ama de casa. La subcontratación o maquila es un acuerdo entre dos establecimientos para que uno confeccione prendas para el otro con o sin el uso de materias primas de éste.

Además, se mencionarán varias categorías de empresas que conviene definir. En cuanto al tamaño, en los capítulos II y III se definen establecimientos muy pequeños los que ocupan hasta cinco personas; pequeños, los que emplean de 6 a 25 personas; medianos, los que tienen entre 26 y 150 trabajadores, y grandes, los que ocupan más de 150 personas. En el capítulo I, el cual se basa en información censal, se utilizan los términos me- 
diano y grande con referencia a establecimientos que tienen enrte 26 y 75 trabajadores, así como más de 75 personas ocupadas, respectivamente. Con respecto a la integración, la total corresponde a fábricas con el proceso completo, desde el diseño hasta el despacho de prendas; la regular se refiere a empresas que tienen la costura y otro departamento más (ya sea diseño, corte o acabado); y las no integradas son las que sólo tienen la costura o las que tienen cualquiera de o todos los otros deartamentos. En lo referente a la antigüerlad, las fábricas antiguas tienen más de 30 años de operaciones; las maduras tienen entre 16 y 30 años; las nuevas, entre 6 y 15 , y las muy nuevas, 5 o menos años. Por último, con respecto a la maquila, los clientes (es decir, subcontratantes) son las empresas que solicitan a otras la manufactura total o parcial de ropa y las maquiladoras (o sea, las empresas subcontratistas) son las que ejecutan las tareas productivas ordenadas por el cliente.

\section{LA EVOLUCIÓN DE LA INDUSTRIA MEXICANA DE LA ROPA DE 1965 A 1975}

\section{Antecedentes}

A principios del presente siglo, existía en el país una base artesanal dedicada a la producción de algunas prendas de vestir hechas de manta y otras telas de algodón. Su importancia era limitada, con respecto a otras actividades productivas que se orientaban al mercado externo. No fue sino hasta después de la Segunda Guerra Mundial, en el momento en que México adoptó una política de industrialización sustitutiva de importaciones, cuando surgieron las primeras fábricas de ropa ya no de tipo artesanal. ${ }^{7}$ El vestuario y otros bienes de consumo no duradero constituyeron el primer conjunto de productos sujetos a la protección de la política referida. De 1940 a 1965, las condiciones económicas generales mejoraron, aumentó el número de establecimientos industriales y se modificaron los hábitos de consumo. En particular, se redujo la importancia de la compra de telas por consumidores para la confección de prendas a la medida y aumentó la demanda de ropa hecha en serie por establecimientos industriales. ${ }^{2}$ Así, en 1945, el valor agregado en la industria local de la ropa, fue de 39 millones de pesos, representando el $11 \%$ del valor agregado en la fabricación de hilados y tejidos de algodón, lana, seda y artisela. ${ }^{3}$ En 1960 , el valor agregado de la ropa fue de 227 millones de pesos y significó una

7. D. Keremitsis, La industria textil mexicana en el siglo XIX, México, Secretaría de Educación Pública, 1973.

2 A. Mercado, Estructura y dinamismo del mercado de tecnología industrial en México. Los casos del poliéster, los productos textiles y el vestido. México, El Colegio de México, 1979 (en prensa). Cap. V.

3 Dirección General de Estadística, Cuarto censo industrial de los Estados Unidos Mexicanas, 1945, Resumen General, México, 1953. 
participación de 19\% con respecto al valor agregado de los hilados y tejidos de algodón, lana y fibras artificiales. ${ }^{4}$

\section{El crecimiento de la producción de ropa, 1965-1975}

En 1965, el valor de la producción bruta de ropa fue de 2260 millones de pesos y su valor agregado fue 1271 millones de pesos. La participación de tales cifras en las correspondientes al total de la industria manufacturera fueron $2 \%$ y $2.9 \%$, respectivamente. ${ }^{3}$ En 1975 , la producción bruta de ropa tuvo un valor de 10000 millones de pesos y el valor agregado fue de 3671 millones de pesos, significando $2.2 \%$ y $2.1 \%$, respectivamente, de los totales agregados de la industria manufacturera. ${ }^{6}$ Considerando que los precios de la ropa en 1975 eran $2.26^{7}$ veces los de 1965 , el valor de la producción a precios constantes aumentó en $95 \%$ y el valor agregado en $28 \%$, en el decenio referido. El mayor crecimiento en la producción bruta que en el valor agregado se debe principalmente a la creciente subcontratación local, lo cual será examinado más adelante. La participación en la producción bruta de la industria manufacturera se conserva casi igual y ello sugiere que el desarrollo industrial ha tenido una influencia en el crecimiento de la manufactura de ropa. Por un lado las medidas que han protegido la producción local de prendas, así como el abastecimiento interno de fibras y textiles, han permitido evitar tanto la competencia con otros países como la necesidad de importar dichas materias primas. Por otro lado, las mejoras en las condiciones económicas generales (reflejadas en el incremento anual del producto interno bruto real per capita superior al 3\% desde 1940) y el crecimiento demográfico elevado (3\% anual desde 1940), han dado lugar a un mercado interno de ropa creciente y amplio, pese a las limitaciones que impone la concentración de los ingresos en una minoría de la población. En 1960, la población de México fue de 36.6 millones y en 1975 se aproximaba a 60 millones de habitantes. ${ }^{8}$

\section{Estructura industrial}

Durante el decenio 1965-1975 se pudieron distinguir dos tipos de fábricas de ropa: una es la que produce ropa exterior y otra que hace ropa interior. Existen diferencias tecnológicas entre ambos que es preciso señalar. El número de empresas del primer tipo ha sido el $97 \%$ de los estable-

4 Dirección General de Estadística, VII Censo Industrial, 1961, Resumen General, México, 1965.

5 Dirección General de Estadística, VIII Censo Industrial, 1965, Resumen General, México, 1967.

6 Dirección General de Estadística, IX Censo Industrial, 1976, Resumen General, México, 1979.

7 Banco de México, Cuentas nacionales 1960-1976, México, 1978.

8 Alba, F., La población de México: evolución y dilemas, México, D. F., El Colegio de México, 1977. 


\section{Cuadro 1}

Distribución DE ESTABLECIMIENTOS EN LA INDUSTRIA MEXICANA DE LA ROPA POR PRODUCTO Y TIPO DE EMPRESA, 1965 Y 1975

(Número de establecimientos)

\begin{tabular}{|c|c|c|c|c|}
\hline \multirow{2}{*}{$\begin{array}{l}\text { Especialidad y tipo } \\
\text { de establecimientos }\end{array}$} & \multicolumn{2}{|c|}{1965} & \multicolumn{2}{|c|}{1975} \\
\hline & Total & 8 & Total & 8 \\
\hline Industria de la ropa & 8886 & 100.0 & 7491 & 100.0 \\
\hline Ropa exterior a/ & 866 в & 96.5 & 7276 & 97.1 \\
\hline Ropa interior E) & 218 & 2.5 & 215 & 2.9 \\
\hline Establecimientos informales & $5 \quad 444$ & 61.3 & 4436 & 59.2 \\
\hline Establecimientos formales & 3442 & 38.7 & 3055 & 40.8 \\
\hline Formales muy pequeños d/ & 2256 & 25.4 & 1587 & 21.2 \\
\hline Formales pequeños ef & 754 & 8.5 & 949 & 12.7 \\
\hline Formales medianos f/ & 316 & 3.5 & 358 & 4.8 \\
\hline Formales grandes $\underline{g} T$ & 116 & 1.3 & 161 & 2.1 \\
\hline
\end{tabular}

Fuente: Dirección General de Estadística, VIII Censo Industrial, 1965, Resumen General y $X$ Censo Industrial, 1976, Resumen General, tomo I, México, D. F., D.G.E., 1967 y 1979.

a Incluye la confección de vestidos, faldas, blusas y otra ropa exterior de mujer, uniformes, trajes, sacos, pantalones, camisas y otra ropa exterior de guantes, panuelos, corbatas y productos similares, ni de suéteres y otros artículos de punto, ni sombreros, gorras y similares, ni otras prendas exteriores de vestir.

b Incluye la fabricación de brasieres, fajas, portaligas y similares, así como la fabricación de otra ropa interior, excepto la tejida de punto.

c Establecimientos sin personal asalariado.

d Empresas con personal asalariado de hasta cinco personas.

e Empresas con personal asalariado, entre 6 y 25 personas.

f Empresas con personal asalariado, entre 26 y 75 personas.

g Empresas con personal asalariado, con más de 75 personas.

Cuadro 2

VALOR AGREGADO EN LA INDUSTRIA MEXICANA DE LA ROPA DE ACUERDO AL BIEN PRODUCIDO Y TIPO DE EMPRESA, 1965 Y 1975

(Millones de pesos corrientes)

\begin{tabular}{|c|c|c|c|c|}
\hline \multirow{2}{*}{$\begin{array}{l}\text { Especialidad y tipo } \\
\text { de establecimiento }{ }^{\prime}\end{array}$} & \multicolumn{2}{|c|}{1965} & \multicolumn{2}{|c|}{1975} \\
\hline & Total & $\because$ & Total & $\%$ \\
\hline Industria de la ropa & 1271 & 100.0 & 3671 & 100.0 \\
\hline Ropa Interior & 1065 & 83.8 & 3138 & 85.5 \\
\hline Ropa interior & 206 & 16.2 & 533 & 14.5 \\
\hline Establecimientos informales & 30 & 2.4 & 105 & 2.9 \\
\hline Establecimientos formales & 1241 & 97.6 & 3566 & 97.1 \\
\hline Formales muy pequeños & 72 & 5.7 & 155 & 4.2 \\
\hline Formañes pequeños & 251 & 19.8 & 60 56 & 17.9 \\
\hline Formales medianos & 364 & 28.6 & 843 & 22.9 \\
\hline Formales grandes & 553 & 43.5 & 1912 & 52.1 \\
\hline
\end{tabular}

FưENTE: Dirección General de Estadística, VIII Censo Industrial, 1965, Resumen General y $X$ Censo Industrial, 1976, Resumen General, tomo I, México, D. F., D.G.E., 1967 y 1979.

a Véanse las notas del cuadro 1. 
Cuadro 3

VALOR AGREGADO Y EMPLEO POR ESTABLECIMIENTO EN LA INDUSTRIA MEXICANA DE LA ROPA DE ACUERDO AL BIEN PRODUCIDO Y TIPO DE EMPRESA, 1965 Y 1975

\begin{tabular}{|c|c|c|c|c|c|}
\hline \multirow[t]{2}{*}{$\begin{array}{l}\text { Especialidad y tipo } \\
\text { de establecimiento af }\end{array}$} & \multicolumn{3}{|c|}{$\begin{array}{l}\text { Valor agregado por } \\
\text { establecimiento } \\
\text { (miles de pesos) }\end{array}$} & \multicolumn{2}{|c|}{$\begin{array}{l}\text { Personas } \\
\text { ocupadas por } \\
\text { establecimiento }\end{array}$} \\
\hline & 1965 & $1975 \mathrm{~b} /$ & $1975 \mathrm{cf}$ & 1965 & 1975 \\
\hline Industría de la ropa & 143 & 216 & 490 & 6 & 9 \\
\hline Ropa exterior & 123 & 190 & 431 & 6 & 8 \\
\hline Ropa interior & 944 & 1096 & 2481 & 23 & 42 \\
\hline Establecimientos informales & 6 & 10 & 24 & $1-3$ & $1-3$ \\
\hline Establecimientos formales & 360 & 516 & 1167 & 14 & 21 \\
\hline Formales muy peque กัos & 32 & 43 & 97 & 3 & 3 \\
\hline Formales pequeños & 333 & 305 & 691 & 12 & 12 \\
\hline Formales medianos & 1152 & 1040 & 2356 & 43 & 44. \\
\hline Formales grandes & 4770 & 5247 & 11880 & 173 & 201 \\
\hline
\end{tabular}

FUENTE: Dirección General de Estadística, VIII Censo Industrial, 1965, Resumen

General y $X$ Censo Industrial, 1976, Resumen General, tomo I, México, D. F., D.G.E., 1967 y 1979.

a Véanse las notas del cuadro 1.

- Valor en precios de 1965.

c Valor en precios corrientes.

d Número de personas.

cimientos manufactureros de ropa en dicho decenio, y han producido el $85 \%$ del total de la manufactura de ropa (véanse los cuadros 1 y 2 ). Pero el aspecto de mayor interés es el de que las fábricas de ropa interior han tenido un tamaño promedio notablemente superior al de las productoras de ropa exterior, tanto en términos de empleo como de producción. El valor agregado del establecimiento promedio de la ropa interior fue el equivalente a 7.7 veces el de la fábrica promedio de la ropa exterior en 1965 y 5.8 veces en 1975; además, aquélla ocupó el cuádruple del número de personas empleadas por la fábrica media de ropa exterior en $1965 \mathrm{y}$ el quíntuple en 1975 (véase el cuadro 3). La primera de estas tendencias parece conducir a una reducción posterior en las diferencias de tamaños pero hoy siguen siendo grandes. Pero esto no se aplica a diferencias de valor agregado por trabajador que, para la industria de ropa interior, fue $90 \%$ más grande que el correspondiente a la ropa exterior en 1965 y $13 \%$ más elevado en 1975 (véase el cuadro 4). La mecanización de las intrincadas operaciones de costura de las partes de la ropa exterior y su ensamble parece haberse acelerado en este decenio, en relación a los avances técnicos incorporados a las unidades productoras de prendas interiores. Ello puede explicar un mayor ritmo de crecimiento de la producción y un menor crecimiento del empleo por establecimiento en el primer caso con respecto al segundo.

En la distribución de tamaños de empresas manufactureras de ropa, destaca la importancia del número de establecimientos informales, concebidos como aquellos que ocupan personal no asalariado. La proporción de estos 


\section{Cuadro 4}

VALOR AGREGADO POR TRABAJADOR EN LA INDUSTRIA MEXICANA DE LA ROPA DE ACUERDO AL BIEN PRODUCIDO Y TIPO DE EMPRESAS, 1965 Y 1975

(Miles de pesos por persona)

\begin{tabular}{|c|c|c|c|}
\hline \multirow[b]{2}{*}{$\begin{array}{l}\text { Especialidad y tipo al } \\
\text { de establecimientos }\end{array}$} & \multirow[b]{2}{*}{1965} & \multicolumn{2}{|c|}{1975} \\
\hline & & $\begin{array}{l}\text { Precios } \\
\text { corrientes }\end{array}$ & $\begin{array}{l}\text { Precios } \\
\text { de } 1965\end{array}$ \\
\hline Industria de la ropa & 23 & 53 & 23 \\
\hline Ropa exterion & 21 & 52 & 23 \\
\hline Ropa interiox & 40 & 59 & 26 \\
\hline Establecimientos informales & 4 & 17 & 8 \\
\hline Establecimientos formales & 26 & 56 & 25 \\
\hline Formales muy pequeños & 12 & 36 & 16 \\
\hline Formales pequeros & 28 & 58 & 25 \\
\hline Formales medianos & 27 & 53 & 24 \\
\hline Formales grandes & 28 & 59 & 26 \\
\hline
\end{tabular}

FUENTE: Dirección General de Estadística, VIII Censo Industrial, 1965, Resumen General y X Censo Industrial, 1976, Resumen General, tomo I, México, D. F., D.G.E., 1967 y 1979.

a Véanse las notas del cuadro 1.

establecimientos ha sido alrededor del $60 \%$ del total de unidades productoras de ropa, entre 1965 y 1975 . El censo de 1975 reveló la existencia de 4436 empresas informales en la manufactura de ropa (véase el cuadro 1). En conjunto, éstas tuvieron bajas participaciones en la producción de ropa: produjeron el $3.6 \%$ y el $1.7 \%$ respectivamente de la producción nacional de prendas en 1965 y 1975. Su participación en el empleo de la rama también descendió de $13 \%$ a $9 \%$, en el mismo periodo. El valor agregado del establecimiento informal medio fue de 6000 pesos en 1965 y 24000 pesos diez años después, representando $1.7 \%$ del valor agregado medio de una empresa formal en el primer año y $2.1 \%$ en el segundo. Dichas cifras significaron el $19 \%$ y $25 \%$, respectivamente, del valor agregado del establecimiento medio formal muy pequeño (con 5 o menos trabajadores) en uno y otro año. Cada establecimiento informal ocupó de una a tres personas en el decenio 1965-1975 (véase el cuadro 3). Durante este periodo, los establecimientos de este tipo doblaron su valor agregado por trabajador a precios constantes, en tanto que el crecimiento de este indicador en el sector formal fue inapreciable. Esto se pudo deber, principalmente, a diferencias en la intensidad del trabajo (mayor en el sector informal) y una tendencia de parte de las fábricas formales a reducir su valor agregado a nivel de planta, subcontratando a terceros cada vez más.

La evolución del sector que ocupa personal asalariado se caracteriza por un aumento en el tamaño de las empresas en el transcurso del tiempo, la concentración industrial en pocas empresas y la mayor eficiencia de los establecimientos pequeños, con un personal ocupado de 6 a 26 personas). 
El valor agregado del establecimiento formal medio aumentó de 360000 pesos en 1965 a 1167000 pesos en 1975 . Si se considera que los precios de las prendas de 1975 eran 2.26 veces los correspondientes a las prendas de $1965,{ }^{9}$ el incremento real fue $40 \%$ (de 360000 a 516000 pesos). Los aumentos de tamaños ocurrieron en empresas muy pequeñas y grandes, en orden de importancia (véase el cuadro 3 ). El número de empresas muy pequeñas se redujo, en tanto que el de empresas grandes aumentó en $40 \%$, el de pequeñas se incrementó en $26 \%$ y el de medianas en $13 \%$ (véase el cuadro 1). El crecimiento limitado de tamaño parece obedecer a presiones competitivas locales que obligan a reducir costos mediante la desintegración del proceso productivo, subcontratando la parte que requiere de más mano de obra (la costura).

En 1965, las empresas grandes eran el 1.3\% de los establecimientos de la industria de la ropa y concentraban el $44 \%$ del valor agregado y el $36 \%$ del empleo de esta rama. Diez años después, las empresas de este tamaño representaban el $2.1 \%$ de las empresas del sector y cubrían el $52 \%$ del valor agregado de la ropa y el $46 \%$ del empleo. Ellas han tenido el mayor valor agregado por trabajador (véanse los cuadros 1,2 y 4 ).

\section{Empleo}

La industria mexicana de la ropa ocupó 56000 personas en 1965 y 70000 en 1975. Este es un incremento cercano al $25 \%$ durante los 10 años del periodo referido, de magnitud similar al crecimiento del valor agregado a precios constantes $(28 \%)$. A través de dichos años, cada incremento de $1 \%$ en el valor agregado real de la ropa tendía a elevar en $0.98 \%$ el empleo. Las cifras sugieren que el comportamiento tecnológico de la industria local de la ropa caracterizado por una lenta mecanización hacía posible que el crecimiento en la producción demandara aumentos en el empleo de similar proporción. Esta situación, varió de acuerdo al tipo de fábricas. Las empresas productoras de ropa exterior tendieron a demandar un $0.92 \%$ más de trabajo por cada $1 \%$ de aumento en el valor agregado, en tanto que las productoras de ropa interior tuvieron una mayor absorción de mano de obra (elasticidad empleo de la producción de 1.7). Las empresas que mayores elasticidades empleo tuvieron fueron las medianas, las pequeñas y las grandes, en orden de importancia. La mayor proporción de empleo en esta industria se concentró en el sector formal -con personal remunerado-, ocupando el $87 \%$ y el $91 \%$ de la mano de obra de la misma rama en 1965 y 1975 respectivamente. Las empresas que mayores niveles de empleo captaron fueron las de tamaño grande (con más de 75 trabajadores) (véase el cuadro 5).

En 1975, el valor agregado de la producción por trabajador en la industria manufacturera fue 106000 pesos, en tanto que en la industria de la ropa fue 51000 pesos. Esta diferencia se asocia a los reducidos pagos al

9 Banco de México, op. cit. 
trabajo per capita. En dicho año, el trabajador promedio de la industria de la ropa recibió 27500 pesos, mientras que el trabajador común de la industria manufacturera ganó 46300 pesos. ${ }^{10}$

\section{La subcontratación ${ }^{11}$ local}

El desarrollo de la industria nacional de la ropa, acompañado por una intensa competencia entre empresas medianas y pequeñas, y el uso de un proceso tecnológico discontinuo, homogéneo y casi sin cambios, estimularon una distribución interfirmas del trabajo por la vía de la subcontratación local de importancia particular en esta rama.

En 1965, la industria manufacturera mexicana registró gastos de 1440 millones de pesos por concepto de pagos por maquila domiciliaria (es de-

\section{Cuadro 5}

DistribuCIÓN DEL PERSONAL OCUPADO EN LA INDUSTRIA MEXICANA DE LA ROPA POR PRODUCTO Y TIPO DE ESTABLECIMIENTO, 1965 Y 1975

(Número de personas)

\begin{tabular}{|c|c|c|c|c|c|c|}
\hline \multirow{2}{*}{$\begin{array}{l}\text { Especialidad y tipo } \\
\text { de establecimientog }\end{array}$} & \multicolumn{2}{|c|}{1965} & \multicolumn{4}{|c|}{$\therefore \quad 1975$} \\
\hline & Total & $\%$ & & tal. & & 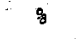 \\
\hline Industria de la ropa & 56069 & 100.0 & 6.9 & 81.6. & & 100.0 \\
\hline Ropa exterior & $50 \quad 972$ & 90.9 & 60 & 771 & & 87.0 \\
\hline Ropa interior & 5097 & 9.1 & 9 & 0.45 & & 13.0 \\
\hline Establecimientos informales & 7508 & 13.4 & 5 & 992 & & 8.6 \\
\hline Establecimientos formales & 48561 & 86.6 & 63 & 824 & & 91.4: \\
\hline Formales muy pequeños & 6152 & 11.0 & 4 & 302 & & 6.1 \\
\hline Formales peque ños & 8915 & 15.9 & 11 & 376 & & 16.3 \\
\hline Formales medianos & 13. 450 & 24.0 & 15 & 828 & & 22.7 \\
\hline Formales grandes & $20 \quad 044$ & 35.7 & 32 & 318 & & 46.3 \\
\hline
\end{tabular}

FueNTE: Dirección General de Estadística, VIII Censo Industrial, 1965, Resumen General y $X$ Censo Industrial, 1976, Resumen General, tomo 1, México, D. F., D.G.E., 1967 y 1979.

a Véanse las notas del cuadro 1.

cir, subcontratación industrial efectuada por establecimientos informales ubicados en viviendas familiares). Estos pagos fueron el $2.4 \%$ del valor agregado $^{12}$ manufacturero. La maquila domiciliaria en la manufactura de ropa fue de 71 millones de pesos, o el $5.7 \%$ del valor agregado en el mismo año (más del doble de la proporción correspondiente al total de la industria manufacturera). La subcontratación del trabajo informal es ligeramente más intensiva en la fabricación de ropa exterior que en el de la ropa interior (véase el cuadro 6).

${ }^{10}$ Dirección General de Estadística (1979), op. cit.

11 Véase la definición de subcontratación en la introducción.

12 El valor agregado se estimó restando el gasto en materias primas, accesorios, envases y empaques del valor de la producción bruta. 


\section{Cuadro 6}

MÉxico: SubCoNTRATACIÓN DE ESTABLECIMIENTOS INFORMALES $Y$ FORMALES EN LAS INDUSTRIAS MANUFACTURERA Y DE LA ROPA, 1965 Y 1975

(Millones de pesos corrientes)

\begin{tabular}{|c|c|c|c|c|c|}
\hline & \multicolumn{3}{|c|}{ Actividad industrial } & \multirow{2}{*}{$\begin{array}{l}\text { Ropa } \\
\text { exterion }\end{array}$} & \multirow{2}{*}{$\begin{array}{c}\text { Ropa } \\
\text { interior }\end{array}$} \\
\hline & Manuf & facturera & Ropa & & \\
\hline \multicolumn{6}{|c|}{1965.} \\
\hline \multicolumn{6}{|l|}{$\begin{array}{l}\text { Subcontratación de trabajo } \\
\text { en domicilios al }\end{array}$} \\
\hline $\begin{array}{l}\text { Total } \\
\text { Valon agregado }(s) d /\end{array}$ & & $\begin{array}{l}443 \\
2.4\end{array}$ & $\begin{array}{r}71.4 \\
5.7\end{array}$ & $\begin{array}{r}62.1 \\
5.8\end{array}$ & $\begin{array}{l}9.3 \\
5.5\end{array}$ \\
\hline Cobrado por subcontratación b/ & 2 & 860 & .255 .4 & 244.6 & 10.8 \\
\hline \multicolumn{6}{|l|}{$\begin{array}{l}\text { Subcontratación de estableci } \\
\text { cimientos c/ }\end{array}$} \\
\hline $\begin{array}{l}\text { Total } \\
\text { Valor agregado }(\%) \text { df }\end{array}$ & 1 & $\begin{array}{l}417 \\
2.3\end{array}$ & $\begin{array}{r}184.0 \\
14.7\end{array}$ & $\begin{array}{r}182.5 \\
16.9\end{array}$ & $\begin{array}{l}1.5 \\
0.9\end{array}$ \\
\hline \multicolumn{6}{|c|}{1975} \\
\hline \multicolumn{6}{|l|}{$\begin{array}{l}\text { Subcontratación de trabajo } \\
\text { en domicilios a/ }\end{array}$} \\
\hline $\begin{array}{l}\text { Total } \\
\text { Valor agregado }(s) d /\end{array}$ & & $\begin{array}{l}748 \\
2.2\end{array}$ & $\begin{array}{r}763.3 \\
14.3\end{array}$ & $\begin{array}{r}691.1 \\
15.5\end{array}$ & $\begin{array}{r}72.2 \\
9.8\end{array}$ \\
\hline Cobrado por subcontratación b/ & 12 & 312 & 849.6 & 734.2 & 115.4 \\
\hline \multicolumn{6}{|l|}{$\begin{array}{l}\text { Subcontratación de estableci- } \\
\text { mientos formales } c /\end{array}$} \\
\hline $\begin{array}{l}\text { Total } \\
\text { Valor agregado }(\%) \text { d }\end{array}$ & 6 & $\begin{array}{l}564 \\
2.5\end{array}$ & $\begin{array}{r}86.3 \\
1.6\end{array}$ & $\begin{array}{r}43.1 \\
0.9\end{array}$ & $\begin{array}{r}43.2 \\
5.9\end{array}$ \\
\hline
\end{tabular}

FUENTE: Dirección General de Estadística, VIII Censo Industrial, 1965, Resumen General y X Censo Industrial, 1976, Resumen General, tomo I, México, D. F., D.G.E., 1967 y 1979.

a Son pagos efectuados durante el año por trabajos hechos por terceros en sus domicilios para los establecimientos, con las materias primas propiedad de éstos.

b Es el monto total de las percepciones que tuvieron los establecimientos durante el año, por concepto del procesamiento de materias primas o de productos semielaborados, propiedad de terceros. Incluye la subcontratación de establecimientos formales e informales.

c Es una estimación basada en deducir lo declarado como pago por la subcontratación hecha por el sector informal en los domicilios de lo declarado como cobros por la subcontratación de establecimientos formales o informales.

d Se estimó una aproximación del valor agregado restando los gastos en materias primas, accesorios, envases y empaques del valor de la producción bruta.

En 1975, los pagos por la maquila domiciliaria fueron 5750 millones de pesos en la industria manufacturera local y significaron el $2.2 \%$ del valor agregado. En la rama de la ropa, lejos de observarse una ligera disminución en su intensidad de maquila informal, se elevó a casi el triple del valor nominal registrado 10 años atrás. La proporción de pagos por 
maquila doméstica con respecto al valor agregado fue $14.3 \%$ y correspondió a un nivel de gastos de 760 millones de pesos en 1975. De nuevo, la intensidad de la subcontratación informal se acentuó en la producción de ropa exterior (véase el cuadro 6).

La subcontratación domiciliaria ha tenido una gran y creciente importancia en la producción de ropa, particularmente la exterior. El valor de la maquila domiciliaria con respecto al valor agregado en la ropa fue poco más del doble de la relación observada en la industria manufacturera en 1965 y seis veces en 1975. Esto parece deberse a un mayor peso de la nómina en la estructura de costos de la industria de la ropa, en comparación con la generalidad de la industria manufacturera. En efecto, mientras la proporción de remuneraciones en el valor agregado se mantuvo alrededor del $29 \%$ en el sector manufacturero durante el período 1965-1975, aumentó de $35 \%$ a $40 \%$ en la manufactura de ropa de uno a otro año (véase el cuiadro 7). Estos coeficientes no toman en cuenta los pagos al trabajo fuera de la empresa. Incorporando los gastos de maquila a los del trabajo dentro del establecimiento principal, resultaría que la participación de remuneraciones en el valor agregado en la actividad manufacturera se redujo de $32 \%$ a $31 \%$, en tanto que en la producción de ropa aumentó de $41 \%$ a $55 \%$, de 1965 a 1975 . El pago al trabajo es muy importante en los costos de la industria de la ropa. Este hecho, en una situación de presiones competitivas locales que exigen reducciones de costos, ha llevado a los productores de ropa a ocupar mano de obra barata vía la subcontratación. El sueldo medio de la industria de la ropa fue de 30800 pesos al año por trabajador y el valor medio de la producción del sector informal fue de 28900 pesos al año por trabajador en 1975. No es exagerado suponer que la remuneración media de este sector esté por debajo de la cantidad mencionada deduciendo los costos en que incurre el establecimiento informal por concepto de energía eléctrica, material, etc. La dife-

\section{Cuadro 7}

\section{Participación del Pago al trabajo en el Valor agregado DE LAS INDUSTRIA MANUFACTURERA Y DE LA ROPA EN MÉXICO, 1965 Y 1975}

\section{(Porcientos)}

\begin{tabular}{lll}
\hline Actividad industrịal & 1965 & 1975 \\
\hline Manufacturera & 29.7 & 28.6 \\
Industria de la ropa & 35.2 & 40.2 \\
Ropa exterion & 35.5 & 36.6 \\
Ropa interior & 33.6 & 62.6 \\
\hline
\end{tabular}

Fuente: Dirección General de Estadística, VIII Censo Industrial 1975 y $X$ Censo Industrial 1976, México, D. F., 1967 y 1979.

a Véase la nota d del cuadro 6 . 
rencia en los niveles de remuneración por horas/hombre puede resultar aun mayor si se considera que las jornadas del sector informal son comúnmente más largas que las del formal, debido al sistema de pago al trabajo del primer sector "a destajo" (según la cantidad de tela cosida o de piezas trabajadas).

Además de la subcontratación de tipo informal, la producción de ropa ha utilizado la maquila de establecimientos formales que ocupan trabajo asalariado. Este tipo de subcontratación tiene menor importancia que la informal én la manufactura de ropa, exceptuando la fabricación de ropa interior. En 1965, la maquila de ropa por empresas formales era de gran magnitud. Era más del doble del valor de la subcontratación informal y su participación en el valor agregado era seis veces la correspondiente a la industria manufacturera. Pero en 1975 la situación fue completamente la opuesta: la maquila formal de ropa fue un décimo del valor de la subcontratación de establecimientos informales y su participación en el valor agregado fue casi la mitad de la participación respectiva del sector manufacturero (véase el cuadro 6).

Lo anterior no se aplica a las fábricas de ropa interior. Ellas observaron un comportamiento de subcontratación muy diferente al resto de la industria de la ropa y algo distinto a la generalidad de la actividad manufacturera. Su intensidad de maquila informal fue el doble de la industria manufacturera en 1965 y el cuádruple en 1975. Pero además, la subcontratación de establecimientos formales en 1975 fue cinco veces más intensa (con respecto al valor agregado) que en 1965, y pasó de ser menor a un décimo de la intensidad en la ropa exterior, a ser cinco veces mayor. De tal manera que la maquila formal en la fabricación de ropa interior ha aumentado su importancia en el transcurso del tiempo, así como con respecto al sector manufacturero y a la especialidad de ropa exterior. La importancia de su maquila informal también ha aumentado en el tiempo.

El periodo 1965-1975, en la industria de la ropa, puede describirse como uno de transición de la subcontratación de empresas formales a la maquila domiciliaria para la fabricación de ropa exterior. Esta tendencia ha sido el resultado tanto de una búsqueda de reducciones de costos vía el empleo de mano de obra barata, como de aspectos tecnológicos. El primer tipo de factores determinantes ya fue apoyado con evidencia líneas atrás. El segundo tipo de factores merece ahora un análisis. El equipamiento de la maquiladora informal de ropa exterior se caracteriza por una - dos máquinas de costura sencillas y baratas. Las tareas de costura efectuadas son rutinarias y simples. La extensión de estas características es amplia, incluso dentro del sector formal; es decir, la relativa sencillez y estabilidad de las técnicas de producción han dado muestras de tener un uso difundido. Por otro lado, la fabricación de prendas interiores como brasieres $y$ fajas requiere de máquinas especiales y costosas, por lo cual la maquila informal en estas especialidades no parece racional. Esto constituye una limitación a la amplitud de la maquila informal, a diferencia de 
la ropa exterior. Las tareas que efectúan los talleres informales parecen relacionarse más con la costura recta de ropa exterior.

\section{La subcontratación internacional}

Por razones similares a las del punto anterior, más de 100 establecimientos locales (en su mayoría ubicados en la frontera norte del país) fueron subcontratados en 1976 y 1977 por empresas extranjeras para la costura de piezas, o su ensamble, de prendas de vestir y calzado. El valor agregado nacional (lo cobrado por maquila) de tales establecimientos fue de 838 millones de pesos en 1976 y 1181 millones en 1977. La primera cifra representa el $8 \%$ del valor de la producción nacional de ropa y un porciento inferior con respecto a la producción local de calzado y vestido. Tal cifra es casi igual al monto cobrado por la maquila interna de ropa en 1975, y ocupa el segundo lugar en importancia, después de los productos eléctricos y electrónicos, de la maquila internacional efectuada en México (el 17\% del ingreso total de divisas por concepto de maquila). Las maquiladoras de exportación de calzado y prendas de vestir son grandes: en promedio, una ocupó 127 personas y tuvo un ingreso de nueve millones de pesos en 1977.

\section{Los mercados interno y externo}

El esquema de política proteccionista de industrialización sustitutiva de importaciones y la existencia de un mercado interno grande, han determinado una escasa participación local en el comercio internacional de ropa. En 1975, el valor aparente del consumo de ropa en México fue de 10083 millones de pesos, de lo scuales 9753 millones fueron ofrecidos por la industria local y 330 millones se importaron..$^{13}$ Las exportaciones de 268 millones de pesos, apenas representaron el $2.7 \%$ del mercado interno en el año referido. Se exporta principalmente ropa exterior (263 millones de pesos en 1975).

\section{Efectos tecnológicos del desarrollo de la industria de la ropa}

La naturaleza dinámica de esta rama desde 1965 ha generado demandas de tecnología incorporada, así como asistencia técnica, capacitación y servicios técnicos específicos. Mientras que al principio la tecnología incorporada provino del exterior, recientemente se inició en el país el ensamble de máquinas industriales de coser (para lo cual se funden algunas piezas sencillas), hay talleres mecánicos especializados en la reparación y adaptación de máquinas de la confección, y se efectúan intercambios de experiencias y programas de capacitación en el corte, la costura y el mantenimiento de maquinaria en escuelas técnicas industriales, Por otro lado, las

13 No se contabiliza el contrabando de ropa norteamericana que se supone ser de gran magnitud. 
relaciones de subcontratación pueden incluir la transferencia de elementos tecnológicos e influir en su difusión hacia empresas informales. Estos vínculos tecnológicos pueden ocurrir tanto en la subcontratación internacional como en la local.

\section{LA TRANSFERENCIA DE TOCNOLOGÍA DE OFERENTES DE MÁQUiNAS A EMPRESAS PRODUCTORAS DE ROPA}

\section{Importancia relativa del comercio de máquinas para la confección}

La compra de maquinaria por las fábricas de ropa tiene poca importancia relativa desde el punto de vista del comercio de bienes de capital hacia la industria manufacturera en México. En 1975, el valor bruto de la maquinaria utilizada en la fabricación de ropa fue 557 millones de pesos, apenas el $0.5 \%$ del monto correspondiente a la industria manufacturera. Una diferencia similar existió en lo relativo a la inversión anual en maquinaria y equipo para la producción. El valor de la maquinaria para la producción de ropa representó el $15 \%$ del valor agregado en esta rama. Éste es un porciento muy bajo si se compara con el correspondiente al total de la industria manufacturera (63\%). La inversión en máquinas que realizó la industria de la ropa en dicho año significó el $2 \%$ del valor agregado, en tanto que la cifra referente a la industria manufacturera fue $8 \%$. Sin embargo, las tasas de expansión de la maquinaria y el equipo (la inversión del año con relación al valor acumulativo de tales bienes de capital) fueron similares en ambos casos se invertía el $13 \%$ en promedio.

El tamaño del mercado de máquinas para la confección de ropa es relativamente pequeño debido, entre otras causas, a su baja participación en la industria manufacturera (véase el capítulo I) y a razones tecnológicas. $\mathrm{Si}$ bien el grado de integración de la fabricación de ropa no es muy diferente del observado por el promedio de las actividades industriales (en el primer caso, la proporción del valor agregado en la producción total es $39 \%$ y en el segundo es menos de $30 \%$ ), la intensidad de capital y el valor de la producción bruta por trabajador plantean diferencias mayores. El valor de la maquinaria y el equipo por trabajador fue 67000 pesos en las industrias manufacturera y extractiva, mientras que resultó ser menos de 10000 pesos en la producción de ropa. El valor de la producción bruta por trabajador fue 67000 pesos en las industrias extractiva y manufacturera fue casi el doble de la correspondiente a la industria de la ropa. Los mayores niveles de mecanización en otras ramas de la industria mexicana y sus mayores volúmenes de producción se traducen en una demanda de máquinas notablemente mayor que en el caso de la fabricación de ropa.

No obstante lo anterior, el tamaño del mercado de maquinaria ha venido creciendo al mismo ritmo que en otras ramas (13\% durante el año de 1975) y su magnitud ha llegado a dejar de ser despreciable. La importancia creciente de la compra de máquinas se concentra en la confección de ropa 
exterior para hombre y en empresas de tamaño grande. El valor de la maquinaria en la especialidad de ropa exterior excepto camisas y uniformes tuvo un monto equivalente al $18 \%$ del valor agregado, superior al promedio de la fabricación de ropa (15\%) en 1975. En las empresas grandes (con producción bruta de más de cien millones de pesos) el porcentaje fue de $23 \%$ en dicho año.

\section{El comercio de máquinas y la transmisión de información técnica}

La oferta de maquinaria y equipo para la confección en México es un canal por el que se transfieren algunos elementos tecnológicos necesarios para la producción de ropa. La vinculación tecnológica entre usuarios y proveedores de máquinas adopta dos formas. Una de ellas consiste en la oferta de información técnica de proveedores a usuarios de máquinas, en la forma de instrucciones para el manejo y el mantenimiento de máquinas y asesoría para hacer adaptaciones mecánicas. La otra forma de relaciones tecnológicas se compone principalmente de una serie de sugerencias y pedidos especiales de innovación o adecuación de máquinas hechos por algunos usuarios a los vendedores de máquinas, quienes a su vez pueden establecer un vínculo similar con los productores extranjeros. La segunda modalidad es poco frecuente y tiene poco impacto en la innovación de las máquinas. ${ }^{14}$

La experiencia de 25 fábricas de ropa indica que mucho conocimiento técnico proveniente de los oferentes de máquinas se transfiere al sector formal, en particular a empresas grandes e integradas. Este conocimiento se relaciona principalmente con ingeniería mecánica. De las fábricas encuestadas, siete son informales y no han recibido servicios ni información técnica de los vendedores de máquinas. Ello es un resultado lógico del hecho de que su fuente principal de maquinaria no es el oferente de máquinas nuevas, sino empresas del mismo ramo del vestido que dan a préstamo o venden máquinas de segunda mano. En tal caso, se espera una mayor relación tecnológica intraindustrial que entre el sector de bienes de capital y el informal de la ropa.

En lo concerniente a fábricas de ropa formales, sólo ocho de 18 declararon haber recibido servicios e información de tipo técnico de las empresas vendedoras de máquinas. Las empresas no integradas (es decir, con sólo una fase del proceso, como el corte) y de tamaños pequeño y muy pequeño virtualmente no adquirieron tecnología desincorporada de tales oferentes. Las fábricas de ropa que relativamente captaron más tecnología del proveedor de máquinas resultaron ser de tamaño grande y totalmente integradas (con el proceso de producción completo, desde el diseño hasta el despacho de prendas). De tres empresas grandes, nueve medianas, cinco

14 A. Mercado, Estructura y dinamismo del mercado de tecnología industrial en México. Los casos del poliéster, los productos textiles y el vestido, México, El Colegio de México, 1979 (libro en prensa), Cap. V 
pequeñas y una muy pequeña encuestadas, las primeras recibieron hasta tres tipos de asistencia técnica del proveedor de máquinas, la mitad de las segundas adquirieron sólo un tipo de asistencia y únicamente un establecimiento pequeño obtuvo un tipo de asistencia. El elemento tecnológico recibido con mayor frecuencia por el grupo de firmas formales visitadas fue la asistencia para el manejo y el mantenimiento de máquinas, captado por siete empresas, de las cuales seis son grandes y medianas, así como totalmente integradas. La asistencia para la selección de máquinas, para la solución de problemas técnicos mecánicos y para la determinación del lay-out, así como la colaboración en la capacitación de mecánicos, fueron adquiridos sólo por empresas grandes y de integración total (véase el cuadro 8).

\section{Cuadro 8}

ASISTENCIA TÉCNICA RECIBIDA POR 18 FÁBRICAS DE ROPA FORMALES PROVENIENTE DE OFERENTES DE MÁQUINAS DESDE EL INICIO DE OPERACIONES HASTA 1979

\begin{tabular}{|c|c|c|c|c|}
\hline Tipo de asisteñcia & $\begin{array}{l}\text { Múmero de } \\
\text { receptoras }\end{array}$ & Grandes $\underline{a} /$ & Medianas & $\begin{array}{l}\text { Totalmente, } \\
\text { integradas }\end{array}$ \\
\hline $\begin{array}{l}\text { A. Instrucciones y asistencia } \\
\text { para el manejo y el mante } \\
\text { nimiento de m-cuinas }\end{array}$ & 7 & 2 & is & 6 \\
\hline $\begin{array}{l}\text { Asistencia para la selec- } \\
\text { cion de máquinas }\end{array}$ & 2 & 2 & 0 & 2 \\
\hline $\begin{array}{l}\text { c. Colaboración en el adiestra } \\
\text { miento de mecánicos }\end{array}$ & 1 & 2 & 0 & 1 \\
\hline $\begin{array}{l}\text { D. Asistencia para la solución } \\
\text { de problemas técnicos }\end{array}$ & 1 & 1 & 0 & 1 \\
\hline $\begin{array}{l}\text { A. Asistencia para la determi } \\
\text { nación del lay-out }\end{array}$ & 1 & 1 & 0 & 1 \\
\hline $\begin{array}{l}\text { No receptoras de asistencia } \pi \mathbf{i} \\
\text { servicios técnicos }\end{array}$ & 10 & 0 & 5 & 4 \\
\hline $\begin{array}{l}\text { Receptoras de solo un tipo de } \\
\text { asistencia }(A-E)\end{array}$ & 6 & 1 & 4 & 5 \\
\hline $\begin{array}{l}\text { Receptoras de dos tipos de asis } \\
\text { tencia }(A-E)\end{array}$ & 1 & 1 & 0 & 1 \\
\hline $\begin{array}{l}\text { Receptoras de tres tipos de asis } \\
\text { tencia }(A-E)\end{array}$ & 1 & 1 & 0 & 1 \\
\hline TotaI & .18 & 3 & s & 11 \\
\hline
\end{tabular}

FUENTE: Investigación directa.

a Con más de 150 personas ocupadas.

b Con empleo de entre 76 y 150 personas.

c Con el proceso productivo completo en el establecimiento; desde el diseño hasta el despacho de ropa.

Los mayores vínculos tecnológicos de los oferentes de maquinaria con las fábricas de ropa de mayor tamaño e integración es producto de la importancia económica que representan éstas como clientes de los primeros. En el mercado mexicano de máquinas industriales de coser hay aproxima- 
damente 15 marcas compitiendo entre sí. ${ }^{15}$ El segmento de demanda constituido por las empresas mayores parece ser el más disputado entre los oferentes de máquinas. Por ejemplo, en 1975 este segmento representó el $28 \%$ del valor de la maquinaria y equipo en la rama de camisas y el $27 \%$ en la ropa interior no de punto, excepto fajas, brasieres y portaligas. EI primer porciento correspondió a las cuatro empresas que tenían más de 100 millones de pesos de producción anual cada una, de un total de 305 fábricas de camisas que fueron censadas. El segundo porciento correspondió a los once establecimientos que habían producido más de 20 millones de pesos cada uno en el año, de 152 fabricantes de ropa interior censados. La importancia económica de estos clientes conduce a los proveedores de maquinaria a ofrecerles un apoyo técnico que consolide su preferencia por una marca de máquinas particular.

\section{RELACIONES TECNOLÓGICAS ENTRE fábRICAS DE ROPA LOCALES}

Además de la relación tecnológica entre oferentes de maquinaria y productores de ropa, existen conexiones interfirmas en el interior del aparato productivo de prendas que indican la posibilidad de una circulación intraindustrial de habilidades, máquinas e información técnica. Tales conexiones pueden ser el movimiento voluntario de trabajo calificado, el préstamo o la comercialización de maquinaria usada, y reuniones o comunicaciones entre empresarios y la maquila local. En este capítulo se examina la importancia de la circulación intraindustrial de tecnología y habilidades, distinguiendo la referente al interior del sector formal, la relativa al sector informal y la existente entre ambos sectores, así como particularizando entre las diversas conexiones interfirmas mediante las cuales se efectúa esta difusión. Para tal propósito, encuestamos a 25 empresas que producen ropa principalmente para el mercado interno ${ }^{16}$ de las cuales siete son establecimientos informales ubicados en viviendas familiares y 18 son empresas formales con una variedad de características, en cuanto a su tamaño, integración, antigüedad, tipo de relación maquiladora y clase de propiedad (véase el cuadro 9).

\section{Magnitud de los vínculos tecnológicos intraindustriales} en los sectores formal e informal

La experiencia de 25 fábricas de ropa sobre la transferencia de tecnología y habilidades sugiere la existencia de un proceso de transición respecto

15 Ibid.

16 El aparato productivo local de ropa destina un $95 \%$ de la producción al mercado interno. Por esta razón y para fines de diferenciar las maquiladoras locales (para la producción nacional) de las maquiladoras de exportación se decidió la distinción referida. Además de las 25 empresas mencionadas, se encuestaron seis maquiladoras de exportación en las que se sustenta el capítulo IV. 


\section{Cuadro 9}

ENCUESTA DE FABRICANTES DE ROPA FORMALES E INFORMALES ORIENTADOS AL MERCADO INTERNO

\begin{tabular}{|c|c|c|c|}
\hline Caracteristicas de empresas a/ & Total & Formales & Informales \\
\hline Total & 25 & 18 & 7 \\
\hline \multicolumn{4}{|l|}{ Tamaño: } \\
\hline Muy peque ño & 8 & 1 & 7 \\
\hline Peque no & 5 & 5 & 0 \\
\hline Mediano & 9 & 9 & 0 \\
\hline Grande & 3 & 3 & 0 \\
\hline \multicolumn{4}{|l|}{ Integración: } \\
\hline TotaI & 11 & 11 & 0 \\
\hline Regular & 4 & 4 & 0 \\
\hline No integrada & 10 & 3 & 7 \\
\hline \multicolumn{4}{|l|}{ Antigue dad: } \\
\hline Antigua & 2 & 2 & 0 \\
\hline Madura & 7 & 6 & 1 \\
\hline Nueva & 10 & 6 & 4 \\
\hline Muy nueva & 5 & 3 & 2 \\
\hline \multicolumn{4}{|l|}{ Relación de maquila: } \\
\hline Cilente & 9 & 9 & 0 \\
\hline Maquiladora & 12 & 5 & 7 \\
\hline No relacionada con maquila & 4 & 4 & 0 \\
\hline \multicolumn{4}{|l|}{ Tipo de propiedad y marca } \\
\hline \multirow{5}{*}{$\begin{array}{l}\text { Cooperativa de participación } \\
\text { estatal, marca nacional } \\
\text { Privada nacional, marca nacional } \\
\text { Privada nacional y marca extran- } \\
\text { jera }\end{array}$} & & & \\
\hline & 1 & 1 & 0 \\
\hline & 23 & 15 & 7 \\
\hline & & & \\
\hline & 2 & 2 & 0 \\
\hline
\end{tabular}

FUENTE: Investigación directa.

a Véanse los conceptos del cuadro en la introducción.

a la fuente de tal transferencia que va desde la oferta de máquinas hasta la relación intraindustrial. También indica una concentración de intercambio de información técnica y la movilidad del trabajo con experiencia en el interior del sector formal.

En promedio, dichas empresas empezaron sus operaciones hace 15 años (algunas comenzaron hace más de $\mathbf{3 0}$ años y otras son muy nuevas), con la adquisición de máquinas e información técnica proveniente del oferente de las mismas. La información incluyó el manejo y mantenimiento de la máquina, así como el lay out y criterios de selección de máquinas. En el transcurso del tiempo, tales empresas acumularon experiencias y desarrollaron cuadros técnicos en ingeniería mecánica, diseño y métodos de producción. También se estimularon intercambios de ideas tanto dentro como fuera de las firmas. Hasta 1979, las fábricas entrevistadas, sin excepción, fueron receptoras o proveedoras de tecnología o trabajo calificado, o realizaron funciones combinadas.

Los medios de transferencia adoptados por la mayoría de las fábricas resultaron ser el movimiento interfirmas de mano de obra con experiencia y la relación de maquila interna. En casi todas las empresas consideradas se observó una deserción y una incorporación de trabajadores con expe- 
riencia previa en el ramo, en busca de mayor salario, prestaciones sociales y seguridad de ingresos por un periodo largo. La movilidad del trabajo, sin embargo, no se repite con frecuencia en cada empresa, a lo largo del tiempo. 18 establecimientos obtuvieron $\mathrm{u}$ ofrecieron cierta información técnica a través de la subcontratación. Sólo nueve fábricas declararon haber recibido o proporcionado intrasectorialmente máquinas de segunda mano, de las cuales la mayoría lo hizo por razones de subcontratación. Otras nueve empresas captaron o dieron ideas y experiencias técnicas, de mercado y administrativa en reuniones o comunicaciones entre empresarios o funcionarios de tales firmas. Esta cooperación técnica se repite con frecuencias irregulares. El grupo de establecimientos encuestados fue más receptor que fuente de tecnología o habilidades para la fabricación de ropa, tanto a nivel global, como por tipo de medio de transferencia (véase el cuadro 10).

El desplazamiento de algunos trabajadores con experiencia de una a otra empresa se efectúa en un contexto de diferenciación de pagos al trabajo por niveles de habilidades y por el tamaño de las fábricas de ropa. En el capítulo I observamos que los salarios por trabajador se incrementan conforme aumenta el tamaño de los establecimientos en esta industria. Algunas empresas medianas se quejan de que algunos operarios y mecá-

\section{Cuadro 10}

MODOS DE TRANSFERENCIA INTRAINDUSTRIAL DE TECNOLOGÍA Y HABILIDADES A/Y POR 25 PRODUCTORES DE ROPA EN MÉXICO, DESDE EL INICIO DE OPERACIONES HASTA 1979

(Número de empresas)

\begin{tabular}{|c|c|c|c|}
\hline $\begin{array}{l}\text { Modos de transferencia de } \\
\text { te cnologia y habilidades }\end{array}$ & Receptoras & Proveedoras & $\begin{array}{l}\text { Receptora } 0 \\
\text { proveedoras }\end{array}$ \\
\hline $\begin{array}{l}\text { Movimiento de trabajadores } \\
\text { con experiencia }\end{array}$ & 22 & 16 & 23 \\
\hline $\begin{array}{l}\text { Compra-venta o prestamo } \\
\text { de mácuinas usadas }\end{array}$ & 7 & 2 & 9 \\
\hline $\begin{array}{l}\text { Reuniones o comunicaciones } \\
\text { entre empresarios }\end{array}$ & 9 & 7 & 9 \\
\hline $\begin{array}{l}\text { Relaciones de stibcontrata- } \\
\text { cion }\end{array}$ & 12 & 6 & 18 \\
\hline $\begin{array}{l}\text { Total de empresas receptoras } \\
\text { o proveedoras }\end{array}$ & 24 & 19 & 25 \\
\hline
\end{tabular}

FUENTE: Investigación directa.

nicos desertan, una vez que ellas les habían ofrecido las oportunidades para elevar su destreza, por la circunstancia de que las mismas no pueden satisfacer sus demandas de salario. De 15 firmas que declararon haber contratado personal con experiencia procedente de otra fábrica de ropa, nueve formales aceptaron personas provenientes del sector informal; en once, los trabajadores venían de empresas de menor tamaño, y sólo dos 
(una de ellas informal) correspondieron a un desplazamiento hacia empresas más pequeñas. En estos dos casos, los trabajadores establecieron dos maquiladoras pequeñas (véase el cuadro 13 ).

La maquila es una relación productiva interempresarial de gran difusión. Las maquiladoras comprenden lo siguiente: 1) todas las empresas informales; 2) la mayoría de las empresas formales pequeñas y muy pequeñas; y 3) algunas empresas formales de tamaño mediano. Los primeros dos rubros representan, respectivamente, el $60 \%$ y el $33 \%$ del número total de establecimientos productores de ropa. En consecuencia, puede estimarse que la subcontratación en esta rama supera el $80 \%$ de los establecimientos locales. Mediante esta relación se pueden transferir algunos elementos tecnológicos. Pero la evidencia sugiere que éstos son limitados y de poco impacto en el status tecnológico de las maquiladoras. En el grupo de empresas que componen nuestra encuesta, se incluyeron 21 establecimientos con relaciones de subcontratación, 9 de ellos son clientes (es decir, principales) y 12 son empresas maquiladoras de diferentes tamaños. En estos casos, ha sido poco el contenido de tecnología que se transfiere vía la maquila. Los principales elementos tecnológicos transferidos fueron relativos a orientaciones sobre normas y control de calidad, así como el préstamo de máquinas de segunda mano (véase el cuadro 11). La información técnica que ofrece el cliente a la maquiladora es la mínima requerida para que las tareas de costura se ejecuten con un bajo índice de devolución de prendas defectuosas (aproximadamente 5\%).

La cooperación técnica entre fábricas de ropa tiene una frecuencia irregular y consiste en el intercambio de información e ideas principalmente sobre la selección, negociación y compra de máquinas, así como la solución de problemas técnicos. Los empresarios captan o proporcionan hasta nueve tipos diferentes de conocimientos técnicos y administrativos (véase el cuadro 11). El intercambio se concentra en el sector formal. De siete establecimientos informales, seis recibieron máquinas en préstamo e instrucciones para la calidad de la maquila; otro obtuvo además orientaciones para la compra de máquinas.

Dentro del sector formal, las mayores conexiones tecnológicas ocurren en empresas grandes y de mayor experiencia. La cooperación entre firmas no muestra depender de la relación de maquila. Por lo general se efectúan reuniones entre personas de fábricas de tamaños similares, por nexos amistosos o comerciales. En tales reuniones se circula información técnica en grupos generalmente reducidos. De 18 fábricas formales, sólo seis captaron o dieron más de tres tipos de información técnica a través de este modo de transferencia, e incluyen tres grandes y con más de 15 años de experiencia.

La fuente de tecnología y habilidades de 16 fábricas formales (dentro de un grupo de 17 receptoras) es el sector formal de la ropa, en tanto que nueve (del mismo grupo) obtienen mano de obra con experiencia procedente del sector informal. La mayor parte de la absorción de tec- 


\section{Cuadro 11}

Habilidades, MÁQUiNAS Y TIPOS DE INFORMACIÓN TÉCNICA TRANSFERIDOS HACIA Y DESDE 25 FÁBRICAS DE ROPA, EN MÉXICO DESDE EL INICIO DE OPERACIONES HASTA 1979

(Número de empresas)

\begin{tabular}{|c|c|c|c|c|c|c|c|c|c|}
\hline \multirow{2}{*}{\multicolumn{2}{|c|}{$\begin{array}{c}\text { Contenido de la } \\
\text { transferencia }\end{array}$}} & \multicolumn{4}{|c|}{ Adquisición } & \multicolumn{4}{|c|}{ Oferta o transferencia } \\
\hline & & \multirow{2}{*}{$\frac{\text { L } \underline{\text { a }}^{\prime}}{-}$} & \multirow{2}{*}{$\frac{k-b /}{-}$} & \multirow{2}{*}{$\frac{c \text { c/ }}{1}$} & \multirow{2}{*}{$\frac{s+d}{11}$} & \multirow{2}{*}{$\frac{\mathrm{t}{ }^{\mathrm{a}}}{-}$} & \multirow{2}{*}{$\frac{\mathrm{K}^{\mathrm{b}} \text { f }}{-}$} & \multirow{2}{*}{$\frac{c-c^{\prime}}{-}$} & \multirow{2}{*}{$\frac{\mathrm{s} \frac{d}{\prime}}{5}$} \\
\hline A. & $\begin{array}{l}\text { Orientaciones sobra } \\
\text { normas y control } \\
\text { de calidad }\end{array}$ & & & & & & & & \\
\hline B. & $\begin{array}{l}\text { Información de dise- } \\
\text { nos y patrones }\end{array}$ & - & - & 1 & 2 & - & - & - & 3 \\
\hline c. & $\begin{array}{l}\text { Préstamo o compra- } \\
\text { venta interfirmas } \\
\text { de máquinas }\end{array}$ & - & 7 & - & 6 & - & 2 & - & 1 \\
\hline & $\begin{array}{l}\text { Movimiento de trabaja } \\
\text { dores con experiencía }\end{array}$ & 22 & - & - & 7 & 16 & - & - & 2 \\
\hline E. & $\begin{array}{l}\text { Información sobre la } \\
\text { selección de máquinas }\end{array}$ & & - & 6 & - & - & - & 5 & - \\
\hline & $\begin{array}{l}\text { Información sobre la } \\
\text { negociación y compra } \\
\text { de máquinas }\end{array}$ & - & - & 6 & - & - & - & 5 & - \\
\hline & $\begin{array}{l}\text { Colaboración para la } \\
\text { capacitación de per- } \\
\text { sonal }\end{array}$ & - & - & 2 & - & - & - & 2 & - \\
\hline & $\begin{array}{l}\text { Asistencia para la so } \\
\text { lución de problemas } \\
\text { tếcnicos }\end{array}$ & - & - & 4 & - & - & - & 3 & - \\
\hline & $\begin{array}{l}\text { Orientaciones sobre } \\
\text { métodos de produc- } \\
\text { ciốn }\end{array}$ & - & - & 2 & - & - & - & $\mathbf{3}$ & - \\
\hline & $\begin{array}{l}\text { Onientaciones sobre } \\
\text { administración }\end{array}$ & - & - & 1 & - & - & - & 2 & - \\
\hline & $\begin{array}{l}\text { Información para el } \\
\text { lay-out }\end{array}$ & - & - & 2 & - & - & - & 2 & - \\
\hline Tot & $\begin{array}{l}\text { al de recepturas o } \\
\text { roveedoras }\end{array}$ & 22 & 7 & 9 & 12 & 16 & 2 & 7 & 6 \\
\hline
\end{tabular}

FUENTE: Investigación directa.

a Movimiento de mano de obra.

b Préstamo o compra-venta de máquinas de segunda mano.

c Cooperación entre empresarios mediante reuniones, cámaras o comunicación limitada en su alcance.

d Relaciones de subcontratación.

nología intraindustrial corresponde a dos empresas grandes $(66 \%$ de las grandes) y una de tamaño pequeño que es maquiladora de otra formal. Esta obtuvo dos elementos de su cliente (instrucciones de calidad y diseños), dos por cooperación técnica y uno por el movimiento de mano de obra. Las dos grandes adquirieron hasta seis elementos, provenientes de empresas extranjeras que ceden derechos de uso de marca. En uno de estos casos, la usuaria de la marca extranjera recibe la información técnica para usarla sin difundirla en ninguna forma. La otra empresa ha reducido 
su relación con la propietaria de la marca extranjera y es la que difunde el mayor número de tipos de conocimientos técnicos del grupo encuestado.

El principal destino de la tecnología difundida por empresas formales es el sector formal (véase el cuadro 16). Las principales fuentes de esta diseminación son una cooperativa grande de participación estatal y otra empresa grande de propiedad privada, usuaria de una marca extranjera pero que ha reducido la influencia del propietario de la marca. Esta empresa recibió información técnica de manera paralela al uso de la marca. En el transcurso del tiempo (más de 30 años) la empresa ha minimizado tales flujos y se muestra más independiente. La otra empresa tiene más de 40 años de experiencia y produce uniformes y calzado para dependencias del gobierno mexicano. Ambas utilizan los servicios de maquiladoras. El principal medio de su provisión de tecnología es la cooperación técnica intraindustrial.

La mayor capacidad de absorción y provisión de habilidades e insumos tecnológicos corresponde a las empresas con acumulación de experiencias y con los cuadros técnicos que reclama el deminio de la tecnología, lo cual se localiza en empresas grandes y algunas medianas de más de 15 años. Es en gran medida por ello que el sector informal tiene poco intercambio intraindustrial de tecnología y es más receptor que proveedor, en comparación con el sector formal.

\section{La transferencia de tecnología hacia y desde el sector informal}

Esta sección se basa en la evidencia obtenida de siete talleres de maquila domiciliaria, con una o dos personas ocupadas, sin salario pero retribuidas según la cantidad de trabajo hecho (pago "a destajo"). En la sección anterior se identificó una transferencia poco dinámica, más receptiva que proveedora y de bajo contenido tecnológico en este tipo de establecimientos, ya sea con relación a firmas formales o a los talleres del propio sector informal (véanse también los cuadros 12, 13, 14, 15 y 16). Las mayores vías de transmisión de tecnología y habilidades son la movilidad de la mano de obra y la relación de maquila que conecta al establecimiento informal con fábricas formales. Ello permite al personal del taller sobrevivir, pero no ha demostrado contribuir a elevar sus status económico y tecnológico.

De los siete talleres, todos recibieron indicaciones sobre la calidad del producto a coser y se establecieron con personal de experiencia que, principalmente por razones socioeconómicas (como madres necesitadas de ingresos pero requeridas en el hogar), decidió tener una máquina de coser en su casa y trabajar ahí para una fábrica o un comerciante. Casi todas las máquinas referidas son de segunda mano, sencillas y se obtuvieron en calidad de préstamo por parte del cliente. El cuadro 14 indica que casi todos los insumos tecnológicos y las habilidades del trabajo han provenido del sector formal. Los establecimientos informales, fuera de poca mano de obra familiar que busca un trabajo asalariado en una fábrica de ropa for- 


\section{Cuadro 12}

TeCNOlOgía Y MANO DE OBRA CALIFICADA ADQUIRIDAS POR 24 FÁbrICAS DE ROPA DE OTRAS EMPRESAS DEL RAMO, DESDE EL INICIO DE OPERACIONES HASTA 1979

(Número de empresas)

\begin{tabular}{|c|c|c|c|}
\hline Tecnologla y habilidedes recibidas & $\begin{array}{l}\text { Receptoras } \\
\text { formales }\end{array}$ & $\begin{array}{l}\text { Receptoras } \\
\text { informales }\end{array}$ & $\begin{array}{l}\text { Total de } \\
\text { receptoras }\end{array}$ \\
\hline $\begin{array}{l}\text { A. Orientaciones sobre normas y control } \\
\text { de calidad }\end{array}$ & 5 & 7 & 12 \\
\hline B. Información sobre diseños y patrones & 3 & 0 & 3 \\
\hline $\begin{array}{l}\text { C. Adquisición de máquinas de segunda } \\
\text { mano }\end{array}$ & 1 & 6 & 7 \\
\hline D. Ingreso de trabajadores calificados & 15 & 7 & 22 \\
\hline $\begin{array}{l}\text { E. Información sobre la selección de } \\
\text { maquinas }\end{array}$ & 6 & 0 & 6 \\
\hline $\begin{array}{l}\text { F. Información para la negociación y } \\
\text { compra de mâquinas }\end{array}$ & 5 & 1 & 6 \\
\hline $\begin{array}{l}\text { G. Colaboración para capacitación de } \\
\text { personal }\end{array}$ & 2 & 0 & 2 \\
\hline $\begin{array}{l}\text { H. Asistencia para la solución de pro } \\
\text { blemas técnicos }\end{array}$ & 4 & 0 & 4 \\
\hline $\begin{array}{l}\text { I. Orientaciones sobre métodos de pro- } \\
\text { ducción }\end{array}$ & 2 & a & 2 \\
\hline J. Orientaciones sobre administraciôn & 1 & 0 & 1 \\
\hline $\begin{array}{l}\text { K. Información para la determinación } \\
\text { del lay-out }\end{array}$ & 2 & 0 & 2 \\
\hline Ninguna categoria (A-K) & 1 & 0 & 1 \\
\hline Receptoras de una o dos categorias $(A-K)$ & 9 & 1 & 10 \\
\hline $\begin{array}{l}\text { Receptoras de tres o cuatro cetegorias } \\
(A-K)\end{array}$ & 5 & $\varepsilon$ & 11 \\
\hline $\begin{array}{l}\text { Receptoras de cinco o seis categorias } \\
(A-K)\end{array}$ & 3 & 0 & 3 \\
\hline Total de receptoras & 17 & 7 & 24 \\
\hline Total de la encuesta & 18 & 7 & 25 \\
\hline
\end{tabular}

FueNTE: Investigación directa.

mal, no ofrece un solo tipo de información técnica a establecimientos formales ni a informales. La única vía de difusión en el interior del sector informal ha sido el adiestramiento de una persona en promedio (familiar del responsable de la maquiladora) por cada una de las siete empresas consideradas, mismo que eventualmente puede establecerse como maquilador informal $u$ ocuparse en el sector formal.

La poca transferencia de tecnología -en un contexto de pobreza y subempleo sufrido por los trabajadores del sector informal- ha hecho muy poco para elevar el status económico y tecnológico de este sector. El número de prendas maquiladas por taller ha sido alrededor de 40 a la semana desde hace años. La costura de maquila ha sido sólo un medio de sobrevivencia para estas personas, 
En seis de los casos referidos los pequeños talleres trabajan para un solo cliente, que es el mismo desde que ellos se establecieron. En tres de ellos, el cliente es el dueño de la fábrica en donde el maquilador trabajaba anteriormente. Ninguno de estos talleres produce directamente para los consumidores, aunque ocasionalmente realizan trabajos sobre pedido para

\section{Cuadro 13}

ORIGEN DE LA TECNOLOGÍA Y LA MANO DE OBRA CALIFICADA RECIBIDAS POR 17 FÁBRICAS DE ROPA FORMALES Y PROVENIENTES DE OTROS PRODUCTORES DE ROPA, DESDE EL INICIO DE OPERACIONES HASTA 1979

(Número de empresas)

\begin{tabular}{|c|c|c|c|}
\hline Tecnologia y habilidades recibidas & $\begin{array}{l}\text { Insumos } \\
\text { procedentes } \\
\text { del sector } \\
\text { formal }\end{array}$ & $\begin{array}{l}\text { Insumos } \\
\text { procedentes } \\
\text { del sector } \\
\text { informal. }\end{array}$ & $\begin{array}{l}\text { Insumos } \\
\text { procedentes } \\
\text { de unou } \\
\text { otro sector }\end{array}$ \\
\hline $\begin{array}{l}\text { A. Orientaciones sobre normas y control } \\
\text { de calidad }\end{array}$ & 5 & 0 & 5 \\
\hline B. Informaciôn sobre diseños y patrones & 3 & 0 & 3 \\
\hline $\begin{array}{l}\text { c. Adquisición de mâquinas de segunda } \\
\text { mano }\end{array}$ & 1 & 0 & 1 \\
\hline D. Ingreso de trabajadores calificados & 13 & 9 & 15 \\
\hline $\begin{array}{l}\text { E. Información sobre la selección de } \\
\text { máquinas }\end{array}$ & 6 & 2 & 6 \\
\hline $\begin{array}{l}\text { F. Información para la negociación } y \\
\text { compra de máquinas }\end{array}$ & 5 & 1 & 5 \\
\hline $\begin{array}{l}\text { G. Colaboración para capacitación de } \\
\text { personal }\end{array}$ & 2 & 0 & 2 \\
\hline $\begin{array}{l}\text { H. Asistencia para la solución de pro } \\
\text { blemas têcnicos }\end{array}$ & 4 & 0 & 4 \\
\hline $\begin{array}{l}\text { I. Orientaciones sobre métodos de pro } \\
\text { ducción }\end{array}$ & 2 & 0 & 2 \\
\hline J. Orientaciones sobre administración & 1 & 0 & 1 \\
\hline $\begin{array}{l}\text { x. Información para la determinación } \\
\text { del lay-out }\end{array}$ & 2 & 1 & 2 \\
\hline Receptoras de una o dos categorías $(A-K)$ & 8 & 6 & 9 \\
\hline $\begin{array}{l}\text { Receptoras de tres o cuatro categorias } \\
\text { (A-K) }\end{array}$ & 5 & 2 & 5 \\
\hline $\begin{array}{l}\text { Receptoras de cinco o seís categorias } \\
(A-K)\end{array}$ & 3 & 1 & 3 \\
\hline Total de receptoras & -16 & 9 & 17 \\
\hline
\end{tabular}

FuENTE: Investigación directa.

algunos consumidores. Un taller de los siete considerados maquila a varias empresas que son pequeños comerciantes de ropa; cuando no realiza trabajos para éstos, el maquilador produce prendas en pequeña escala para venderlas por su cuenta a algunas tiendas de ropa. De los 7 pequeños talleres visitados 4 de ellos es especializan en producir un solo tipo de artículo. 


\title{
Cuadro 14
}

\begin{abstract}
ORIGEN DE LA TECNOLOGÍA Y EL TRABAJO CALIFICADO RECIBIDOS POR SIETE ESTABLECIMIENTOS INFORMALES PROVENIENTES DE OTRAS FÁBRICAS DESDE EL INICIO DE OPERACIONES HASTA 1979
\end{abstract}

\begin{tabular}{|c|c|c|c|c|c|}
\hline Tecnologia y habilidades recibidas & $\begin{array}{l}\text { Insumos } \\
\text { provenientes } \\
\text { del sector } \\
\text { formal }\end{array}$ & $\begin{array}{l}\text { Insumos. } \\
\text { provenientes } \\
\text { del sector } \\
\text { informal }\end{array}$ & $\begin{array}{r}\text { In } \\
\text { prove } \\
\text { de. } \\
\text { otro }\end{array}$ & $\begin{array}{l}\text { sumos } \\
\text { anien } \\
\text { uno } \\
\text { sect }\end{array}$ & $\begin{array}{l}\text { os } \\
\text { utes } \\
\text { utor }\end{array}$ \\
\hline $\begin{array}{l}\text { I. Orientaciones sobre normas y con- } \\
\text { trol de calidad }\end{array}$ & 7 & 0 & & 7 & \\
\hline $\begin{array}{l}\text { II. Adquisición de máquinas de segụ } \\
\text { da mano }\end{array}$ & $\mathbf{5}$ & 1 & & 6 & \\
\hline $\begin{array}{l}\text { IrI. Ingreso de trabajadores con expe } \\
\text { riencia fabril }\end{array}$ & 6 & 1 & & 7 & \\
\hline $\begin{array}{l}\text { IV. Infórmación sobre Ia negociación } \\
\text { y compra de máquinas }\end{array}$ & 0 & 1 & & 1 & \\
\hline $\begin{array}{l}\text { Receptoras de dos tipos de tecnologia } \\
\text { o habilidades (I-I.V) }\end{array}$ & 1 & 0 & & $\therefore$ & \\
\hline $\begin{array}{l}\text { Receptoras de tres tipos de tecnologia } \\
\text { o habilidades (I-IV) }\end{array}$ & 5 & 1 & & 5 & \\
\hline $\begin{array}{l}\text { Receptoras de cuatro tipos ae tecrolo } \\
\text { gia o habilidades (I-IV) }\end{array}$ & 1 & 1 & & 1 & \\
\hline Total de receptoras & 7 & 2 & & 7 & \\
\hline
\end{tabular}

FUENTE: Investigación directa.

\section{SUBCONTRATACIÓN INTERNACIONAL Y ABSORCIÓN LOCAL DE TECNOLOGÍA}

En México (principalmente en la zona fronteriza norte), hay más de 100 empresas que efectúan tareas de costura de ropa con materiales de empresas localizadas en el extranjero. En promedio, estas maquiladoras son grandes (cada una ocupa más de 100 trabajadores) y, en consecuencia parecen tener cierta capacidad de absorber información técnica de las empresas principales. Sin embargo, las posibilidades de absorción de tecnología dependen de la magnitud, frecuencia y tipo de conocimientos tecnológicos que se transfieren. Estos factores parecen depender a su vez de la estructura de propiedad de la maquiladora y el tipo de trabajo efectuado por ella. A continuación se analiza esta relación con base en la experiencia de seis empresas maquiladoras de exportación establecidas en Mexicali, Baja California, en la zona norte del país. Dos de ellas son de capital mixto (joint venture) con relativa independencia de las empresas principales, dos son nacionales cooperativas y una es nacional y privada con relativa independencia.

\section{El caso de dos maquiladoras de capital totalmente extranjero}

Estas empresas en realidad constituyen unidades de producción de empresas norteamericanas. Su organización y funcionamiento dependen ente- 


\section{Cuadro 15}

TeCNología Y MANo DE OBRA CALIFICADA QUE HAN SALIDO DE 19 PÁBRICAS DE ROPA HACIA OTRAS DEL MISMO RAMO DESDE EL INICIO DE OPERACIONES HASTA 1979

\begin{tabular}{|c|c|c|c|}
\hline Trabajo calificado y tipo de tecnologia & $\begin{array}{l}\text { Proveedoras } \\
\text { formales }\end{array}$ & $\begin{array}{l}\text { Proveedoras } \\
\text { informales }\end{array}$ & $\begin{array}{c}\text { Toțal da } \\
\text { provédoras }\end{array}$ \\
\hline $\begin{array}{l}\text { A. Orientaciones sobre normas y control. } \\
\text { de calidad }\end{array}$ & $E$ & 0 & .5 \\
\hline B. Información sobre disefios y patrones & 3 & 0 & 3 \\
\hline $\begin{array}{l}\text { c. Venta o concesión en prestamo de mä- } \\
\text { quinas de segunda mano }\end{array}$ & 2 & 0 & 2 \\
\hline $\begin{array}{l}\text { D. Deserción de trabajadores califica- } \\
\text { dos }\end{array}$ & 14 & 2 af & 16 \\
\hline $\begin{array}{l}\text { E. Información sobre la selección de } \\
\text { máquinas }\end{array}$ & 5 & 0 & 5 \\
\hline $\begin{array}{l}\text { F. Información para la negociación } y \\
\text { compra de máquinas }\end{array}$ & 5 & 0 & 5 \\
\hline $\begin{array}{l}\text { 6. Colaboración para la capacitación } \\
\text { de personal. }\end{array}$ & 2 & 0 & 2 \\
\hline $\begin{array}{l}\text { H. Asistencia para la solución de pro } \\
\text { blemas técnicos }\end{array}$ & $\mathbf{3}$ & 0 & 3 \\
\hline $\begin{array}{l}\text { I. Oxientación sobre metodos de produe } \\
\text { ción }\end{array}$ & 3 & 0 & 3 \\
\hline J. Orientaciones sobre adrinistración & 2 & 0 & 2 \\
\hline $\begin{array}{l}\text { K. Informacion para la determinación } \\
\text { del lay-out }\end{array}$ & 2 & o & 2 \\
\hline $\begin{array}{l}\text { 8in cooperación tếcnica ni transferencia } \\
\text { pasiva de habilidades }\end{array}$ & 1 & 5 & 6 \\
\hline $\begin{array}{l}\text { Proveedoxas de uno o dos tipos de tecro- } \\
\text { logla o habilidades }(A-K)\end{array}$ & 12 & 2 & 14 \\
\hline $\begin{array}{l}\text { Proveedoras de tres o cuatro tipos de } \\
\text { tecnolog a o habilidades }(A-K)\end{array}$ & 2 & 0 & $\dot{2}$ \\
\hline $\begin{array}{l}\text { Proveedoras de cinco o seis tipos do } \\
\text { tecnologia o habilidades }(A-K)\end{array}$ & 1 & 0 & 1 \\
\hline $\begin{array}{l}\text { Proveedoras de siete u ocho tipos de } \\
\text { tecnologia o habilidades (A-K) }\end{array}$ & 2 & 0 & 2 \\
\hline Total de proveedoras & 17 & 2 & 19 \\
\hline Iotal de la encuesta & 18 & 7 & 25 \\
\hline
\end{tabular}

FUENTE: Investigación directa.

a En un establecimiento, la mano de obra con experiencia se movió al sector formal, en tanto que en el otro se desplazó a los sectores formal e informal.

ramente de las decisiones de la casa matriz. Ellas contratan personal mexicano para sus puestos directivos, el cual es entrenado en la casa matriz de Estados Unidos y tienen la responsabilidad de realizar los planes de organización y producción de las empresas maquiladoras. Las maquiladoras estudiadas son de tamaño grande y cuentan con un promedio de antigüedad de 11 años.

Una de estas empresas está integrada totalmente, aunque sólo en ocasiones se hace uso del departamento de corte, cuando la matriz no envía los cortes hechos. La otra maquiladora no está integrada totalmente (se especializa en el ensamble y el cosido de algunas piezas de ropa). 


\section{Cuadro 16}

DESTINO DE LA TECNOLOGÍA Y EL TRABAJO CALIFICADO EGRESADOS DE 18 FÁBRICAS DE ROPA FORMALES Y CAPTADOS POR EMPRESAS DEL RAMO DESDE EL INICIO DE OPERACIONES HASTA 1979

\begin{tabular}{|c|c|c|c|}
\hline Trabajo calificado y tipo de tecnologia & $\begin{array}{l}\text { A empresas } \\
\text { formales }\end{array}$ & $\begin{array}{l}\text { A empresas } \\
\text { informales }\end{array}$ & $\begin{array}{c}\text { A uno u } \\
\text { otro tipo } \\
\text { de empresas }\end{array}$ \\
\hline $\begin{array}{l}\text { A. Orientaciones sobre normas y control } \\
\text { de calidad }\end{array}$ & 4 & 1 & 5 \\
\hline B. Información sobre diseños y patrones & 3 & 0 & 3 \\
\hline $\begin{array}{l}\text { c. Venta o concésión en préstamo de mâ- } \\
\text { quinas de seg-nda mano }\end{array}$ & 2 & 0 & 2 \\
\hline $\begin{array}{l}\text { D. Deserción de trabajadores califica- } \\
\text { dos }\end{array}$ & 13 & 4 & 14 \\
\hline $\begin{array}{l}\text { E. Información sobre la selección de } \\
\text { máquinas }\end{array}$ & 5 & 2 & 5 \\
\hline $\begin{array}{l}\text { F. Información para la negociación } y \\
\text { compra de máquinas }\end{array}$ & $\mathbf{5}$ & 1 & 5 \\
\hline $\begin{array}{l}\text { G. Colaboración para la capacitación } \\
\text { de personal }\end{array}$ & 2 & 0 & 2 \\
\hline $\begin{array}{l}\text { H. Asistencia para la solución de pro- } \\
\text { blemas técnicos }\end{array}$ & 3 & 0 & $\mathbf{3}$ \\
\hline $\begin{array}{l}\text { I. Orientacianes sobre métodos de pro- } \\
\text { duccion }\end{array}$ & 3 & o & 3 \\
\hline J. Orientaciones sobre administración & 2 & 0 & 2 \\
\hline $\begin{array}{l}\text { K. Información para la determinación } \\
\text { del lay-out }\end{array}$ & 2 & 1 & 2 \\
\hline $\begin{array}{l}\text { Proveedoras de uno o dos tipos de tec- } \\
\text { nologia o habilidades }(A-K)\end{array}$ & 12 & 3 & 12 \\
\hline $\begin{array}{l}\text { Proveedoras de tres o cuatro tipos de } \\
\text { tenologia o habilidades }(A-K)\end{array}$ & 2 & 2 & 2 \\
\hline $\begin{array}{l}\text { Proveedoras de cinco o seis tipos be } \\
\text { tecnologia o habilidades (A-K) }\end{array}$ & 1 & 0 & 1 \\
\hline $\begin{array}{l}\text { Proveedoras de siete u ocho tipos de } \\
\text { tecnologia o babilidades }(\mathrm{A}-\mathrm{K})\end{array}$ & 2 & 1 & 2 \\
\hline Total de proveedoras & 17 & 6 & 17 \\
\hline
\end{tabular}

FUENTE: Investigación directa.

Estas empresas no tienen vínculos tecnológicos con otras del ramo ubicadas en Mexicali, ya que por ser filiales mantienen en secreto los diseños de sus matrices y su comportamiento depende de las políticas de éstas.

La matriz es la principal fuente de elementos tecnológicos e insumos necesarios para la producción. No obstante que cuentan con infraestructura técnica (departamento mecánico para el mantenimiento preventivo y correctivo y para realizar algunas adaptaciones menores), las maquiladoras evidencian una dependencia tecnológica considerable con respecto a la matriz. La casa matriz proporciona asistencia técnica relacionada con la selección de maquinaria, la organización de la planta (lay-out), implantación de sistemas de administración, control de calidad de las prendas producidas y los diseños y patrones de los productos. Este último elemento es transferido frecuentemente incorporado en cortes de tela. 


\section{El caso de dos maquiladoras independientes}

La matriz proporciona maquinaria, refacciones y accesorios para las máquinas y toda la materia prima para las prendas de vestir (hilos, telas, botones, etc.). Ella ha llegado a establecer un sistema de inspección (ejecutado por la misma) para vigilar la eficiencia de producción y las normas de calidad de las prendas. En particular, esta empresa principal proporciona especificaciones detalladas sobre las operaciones a realizarse para la producción y la estandarización del tiempo requerido para cada operario que las lleve a cabo. La matriz también ofrece a las maquiladoras "prendasmodelo" que sirven de guía del trabajo de maquila.

El desarrollo de habilidades de los operarios se fundamenta en algunos cursos de capacitación formal y en la experiencia acumulada en maquiladoras. Una de las dos maquiladoras consideradas, cuyas prendas deben ser de gran calidad y requiere mano de obra especializada, prefiere contratar personal sin experiencia, a fin de desarrollar y adaptar su destreza acorde con los métodos de trabajo específicos de la maquiladora. La otra maquiladora capacita su personal sobre la marcha del trabajo y en colaboración con un Centro de Capacitación para el Trabajo Industrial (CECATI). La colaboración entre la última maquiladora mencionada y el CECATI fue provechosa para tal empresa. El adiestramiento de operarios de máquinas se efectuó cuando la maquiladora iniciaba sus actividades.

Los CECATI suelen coordinarse con las maquiladoras de la frontera para adiestrar tanto operarios como técnicos mecánicos de la rama del vestido. Ellos establecen programas de capacitación en colaboración con las empresas que requieren personal. La preparación de operarios consiste en la instrucción básica con respecto a la operación y el funcionamiento de las máquinas. La maquiladora facilita el uso de sus máquinas $\mathrm{y}$, cuando la capacitación concluye, selecciona personal entre las personas adiestradas. El CECATI ofrece también cursos básicos para técnicos de mantenimiento.

Una de estas empresas es de capital nacional y la otra es de capital mixto. Cada una de ellas maquila a varias matrices del extranjero. Son de tamaño mediano y su grado de integración es parcial, puesto que se concentran en la costura. En tareas de costura, se dedican más al ensamble. En ocasiones el ensamble es incompleto porque se excluyen el ojalado y el botonado por razones de costos.

Las empresas trabajan 10 meses al año, debido a que durante los meses de diciembre y enero las compañías extranjeras para las cuales trabajan cierran sus plantas por vacaciones al personal o bien por haber cumplido con sus programas de producción del año.

Los responsables de las maquiladoras acumularon experiencias técnicas y administrativas en otras empresas filiales de capital extranjero. Luego de independizarse, estableciendo las maquiladoras en consideración, ellos establecieron sus propios sistemas administrativos, organizativos y productivos. 
La vinculación entre estas maquiladoras independientes y sus clientes extranjeros es considerable. De manera similar al caso anterior, las empresas matrices proporcionan instrucciones, "prendas-modelo", secuencias de operaciones y los tiempos y movimientos del trabajo, para lograr la cantidad, calidad, estilos, etc. de las prendas que se requiere a costos bajos. En el caso de la empresa de capital mixto, el cliente envía periódicamente un inspector que revisa el funcionamiento en la línea de producción y la calidad de las prendas y, en caso necesario, recomienda cambios. En pocas palabras, las maquiladoras obtuvieron de sus clientes información sobre normas de calidad, balanceo de la línea de producción y mejoras en los métodos de producción. Además de la relación tecnológica, cabe mencionar que también existen vínculos de tipo financiero.

La gran relación tecnológica con las matrices no ha constituido en sí un obstáculo para la difusión de algunos (pocos) elementos tecnológicos. Por ejemplo, la maquiladora de capital nacional ha tenido experiencias ocasionales de diseño y confección de chaquetas para algunos almacenes de ropa locales.

Estas maquiladoras independientes cuentan con infraestructura técnica para dar mantenimiento preventivo y correctivo a las máquinas. Sus departamentos mecánicos han realizado pequeñas adaptaciones y modificaciones al equipo que han facilitado su operación y ayudado al manejo más eficiente de los materiales utilizados en la fabricación. También han mejorado la calidad del producto. No han requerido de asistencia técnica para solucionar problemas de manejo, mantenimiento, reparación y modificación de máquinas.

El tipo de decisiones tecnológicas que las maquiladoras independientes han hecho de manera autónoma son las referentes a la selección de maquinaria, la organización de la planta, la capacitación de operarios y los sistemas de administración. La capacitación de mecánicos se lleva a cabo en coordinación con el CECATTI.

La capacitación de personal de reciente ingreso en las maquiladoras no se compone de una serie de cursos formales, sino del desarrollo de la destreza por vía de la instrucción práctica. En dicho tipo de capacitación, las maquiladoras distinguen dos tipos de personal de reciente incorporación: con experiencia y sin experiencia. El primer grupo de trabajadores necesita poco adiestramiento, restringiéndose sólo a un "ajuste" para los tipos de máquinas y métodos de producción de la maquiladora en cuestión. $\mathrm{El}$ segundo tipo de personas requieren indicaciones básicas y supervisores.

La maquinaria en uso comprende una proporción elevada $(50 \%)$ de máquinas de segunda mano. Toda la maquinaria y el equipo proceden de Estados Unidos.

\section{El caso de dos maquiladoras organizadas como cooperativas}

La actividad productiva de estas cooperativas maquiladoras se restringe a la costura. Una es de tamaño mediano y otra es pequeña. Estas origi- 
nalmente eran maquiladoras filiales de compañías norteamericanas. En 1976, a raíz de la devaluación del peso y de problemas laborales (sindicalización y demandas de aumentos salariales y de prestaciones sociales), se suscitaron huelgas que dieron como resultado el cierre de estas maquiladoras, las cuales otorgaron la maquinaria y el equipo a los trabajadores como pago de indemnizaciones. Con los bienes de capital en su poder, los trabajadores se organizaron en pequeñas empresas cooperativas y siguieron funcionando como maquiladoras para empresas extranjeras. Bajo esta forma de organización, los nuevos socios (extrabajadores de filiales) absorben los gastos de operación y las remuneraciones son pagos a destajo (según el número de prendas por jornada). El personal administrativo es elegido por la sociedad cooperativa de entre sus miembros.

Estas cooperativas trabajan para varios clientes. Pero su contacto no es directo. Este se logra por intermediarios. La intermediación del vínculo entre clientes y maquiladoras se debe en buena medida a la escasez de relaciones de los socios cooperativistas con empresas matrices, su desconocimiento del idioma inglés y su inexperiencia en la negociación de pedidos de maquila. El intermediario o "representante" posee estos requisitos y domina los conocimientos pragmáticos de las prácticas aduanales y tributarias. El "representante" puede buscar maquiladoras cooperativas o clientes para éstas. Una vez establecido el contacto entre matriz y maqujladora, la función del "representante" termina al establecerse el contrato de maquila o puede cubrir tareas de asesoría para la cooperativa hasta la conclusión de dicho contrato.

La tecnología en uso tiene elementos definidos por las matrices de las que antes eran filiales. En la cooperativa de tamaño pequeño, la selección de máquinas, los sistemas de administración y la capacitación de los operarios y mecánicos fueron decididos por la matriz (la capacitación se hizo en coordinación con el ceCati). Pero la cooperativa también ha tomado decisiones tecnológicas. La organización de la planta fue realizada por la propia empresa al establecerse como cooperativa. En el caso de la empresa mediana, la selección de las máquinas, la organización de la planta, la administración y la capacitación de operarios y técnicos fue realizada por la propia empresa. Las cooperativas prefieren contratar su personal con experiencia en la fabricación de ropa debido a que el salario es a destajo. Han difundido habilidades entre otras empresas locales a través del movimiento de la mano de obra.

Los elementos tecnológicos que ellas reciben de los clientes son los siguientes: normas de calidad, especificaciones de la prenda (secuencia de operaciones), diseños y patrones. También reciben de los clientes los insumos requeridos para el ensamble de la prenda de vestir (tela cortada, forros, entretelas, broches de presión, agujas, etc.) y, ocasionalmente, financiamiento para la compra de maquinaria.

Las cooperativas cuentan con infraestructura técnica para el mantenimiento preventivo y correctivo de las máquinas. En el caso de la coopera- 
tiva mediana, su departamento mecánico ha modificado máquinas para facilitar su operación y adecuarla a los materiales utilizados. La maquiladora no ha demandado asistencia técnica para el mantenimiento de sus máquinas. En el caso de la cooperativa pequeña, ésta no ha modificado sus máquinas, pero ha requerido la asistencia técnica de un mecánico externo a la empresa, cuando surge un problema técnico que su departamento mecánico no puede resolver.

\section{CONCLUSIONES}

En los capítulos anteriores se ha presentado evidencia de que el desarrollo de la industria mexicana de la ropa ha tenido las siguientes características: $a$ ) ha sido sujeta a medidas proteccionistas; $b$ ) su tasa de crecimiento ha sido similar a la de la industria manufacturera; $c$ ) su desarrollo ha sido impulsado tanto por la mejora de las condiciones económicas generales como por el crecimiento demográfico; y $d$ ) evidencia una elevada concentración industrial. Estas características han dado lugar a un cambio en los mecanismos de transferencia de tecnología en el transcurso del tiempo: de la importación de tecnología incorporada al intercambio local de tecnología desincorporada. Estos vínculos tecnológicos se concentran en empresas grandes, integradas y con un periodo largo de experiencia.

La importación de máquinas para la fabricación de ropa es relativamente baja con respecto a la de otro tipo de maquinaria y de acuerdo a su peso en el valor agregado. Ello se debe a la reducida importancia del valor de la producción nacional de ropa en el sector manufacturero y al bajo nivel de mecanización. Estos factores se están modificando en el tiempo y, en consecuencia, la demanda de máquinas para la confección tiende a incrementarse, en particular en la especialidad de la ropa exterior y en fábricas grandes. Mediante el comercio de máquinas nuevas se transmite información técnica (generalmente de ingeniería mecánica) de los oferentes a los usuarios. Esta transferencia se orienta casi totalmente al sector formal de la ropa, sobre todo a empresas grandes e integradas. Esto obedece a la gran importancia económica de estas empresas como clientes de vendedores de máquinas que sostienen una fuerte competencia entre sí. El sector informal está completamente segregado de este tipo de transferencia de tecnología, ya que su demanda de máquinas nuevas es casi nula, muy inferior a su pequeña demanda de maquinaria de segunda mano.

La transferencia de tecnología intraindustrial es de mayor amplitud que la proveniente de los oferentes de maquinaria. La primera implica el desarrollo de cuadros técnicos y el aprendizaje tecnológico en las fábricas de ropa. Este desarrollo tecnológico tiende a difundirse ampliamente entre dichas fábricas por varios mecanismos. La transferencia vía la oferta de maquinaria es menos importante debido al ritmo lento de innovación tecnológica incorporada en las máquinas y su difusión limitada. 
Los medios de transferencia intraindustrial de tecnología y habilidades más utilizados son el movimiento de trabajadores con experiencia, la subcontratación y la cooperación técnica entre empresas. Estos son los mecanismos de circulación tecnológica en el sector formal. El primero y el segundo generan vínculos tecnológicos entre los sectores fromal e informal. Sólo el adiestramiento familiar es el medio de difusión de habilidades en el interior del sector informal. El mayor contenido de tecnología se transmite a través de la cooperación técnica entre establecimientos formales.

La mano de obra con experiencia tiende a desplazarse de una empresa a otra de mayor tamaño, en busca de mejor remuneración. En el sector informal, las habilidades desarrolladas por el adiestramiento familiar tienden a moverse al sector formal o al establecimiento de su propia unidad informal, intentando lograr un ingreso seguro por un periodo largo.

La tecnología que se transfiere mediante la maquila se compone del mínimo de elementos que permite una proporción reducida de devoluciones de prendas defectuosas. Esta transferencia es parcial y de poco beneficio para la receptora. La maquila es en esencia una forma de organización del trabajo que responde a la necesidad de las empresas principales de reducir el peso de la nómina en la estructura de costos.

La cooperación técnica entre empresas formales contiene hasta nueve elementos tecnológicos. Se polariza en empresas grandes y con más de 15 años de establecidas, cuyo personal administrativo y técnico se reúne en pequeños grupos para intercambiar ideas y experiencias tecnológicas y de mercado.

Los establecimientos informales, generalmente talleres de costura de una a tres personas, ubicados en una parte de una vivienda, son receptores de poca tecnología. La obtienen por la relación de maquila. El aprendizaje que se puede obtener en este caso se difunde de forma limitada a través del trabajo en un círculo familiar. La adquisición de orientaciones para la costura, dadas por la empresa cliente, sólo permite sostener la existencia del establecimiento (con bajos porcentajes de devolución de mercancía). La capacitación familiar ha permitido el aumento del ingreso familiar cuando las personas adiestradas encuentran un empleo en el sector formal. Las principales limitaciones del progreso de un establecimiento informal son: la dependencia de un solo cliente; su marginación, tanto de los mercados financieros de insumos y productos, como de la política económica; y la falta general de recursos a su disposición.

Puesto que la fabricación de ropa es intensiva en trabajo - sobre todo en la costura- y usa un proceso tecnológico homogéneo, tradicional y discontinuo, la búsqueda de costos bajos en la producción mundial ha conducido a empresas norteamericanas a la subcontratación de establecimientos localizados principalmente en la frontera norte de México. La maquila de ropa de exportación tiene una importancia elevada con respecto a la subcontratación en otras ramas manufactureras, en términos de empleo e ingreso de divisas. Su impacto tecnológico depende de las condiciones 
en que se efectúe la relación de maquila. A menor tamaño, a mayor participación extranjera en el capital social, a mayor dependencia de una o algunas firmas principales o de intermediarios, y a menor integración de la maquiladora, se observan menores oportunidades de absorción y diseminación de tecnología.

Una política estatal que tenga como objetivo la elevación del nivel económico y tecnológico del sector informal (amplio) de la industria local de la ropa, tiene que tomar en cuenta las implicaciones que provienen de este informe. Es decir, si la maquila continúa sin un control por parte del Estado y sigue a merced de la oferta y la demanda, y mientras la transferencia de tecnología se concentre en las empresas más grandes, el sector formal - sobre todo las firmas grandes- seguirá fortaleciendo sus cuadros técnicos, acumulando un aprendizaje tecnológico y difundiendo tecnología y habilidades en su interior, en tanto que el sector informal continuará marginado, maquilando, dependiente y sin progresos notables en su status económico y tecnológico.

Si las diferencias entre los sectores formal e informal siguen creciendo, será cada vez más difícil la existencia de los talleres maquiladores domésticos. Ellos podrían tender a desaparecer por insuficiencia relativa de ingresos. Lo cual podría estimular un aumento en las tensiones sociales locales, porque tales talleres son una fuente importante de trabajo de gente subempleada. Por ello y puesto que en los establecimientos informales hay habilidades que pueden ser aprovechadas y desarrolladas, no resulta aconsejable su extinción. Lo ideal sería que ellos dejaran de ser informales y llegaran a ser formales, pero la evidencia de este estudio indica que esto no sucede en la realidad.

\section{ANEXO \\ DESCRIPCIÓN DEL PROCESO TECNOLÓGICO PARA LA FABRICACIÓN DE ROPA}

\section{Diseño y determinación de patrones}

Los patrones norman las dimensiones y estilos de las prendas. Ellos están determinados por el diseño del producto que a su vez dependen en buena medida del factor moda. El diseño está orientado generalmente a la proyección de la prenda en la sección de mercado que cubre la empresa en cuestión. El diseño y el establecimiento de patrones pueden estar apoyados en actividades de investigación y desarrollo experimental, estudios actualizados de las complexiones más frecuentes de las personas usuarias por regiones, y técnicas de computación para optimizar el uso de la tela. La creatividad en el diseño depende de la política y los recursos de las empresas. Parece ser usual que la mayoría de los confeccionistas imiten los diseños y patrones de mayor éxito comercial. Entre las empresas de escasos o 
medianos recursos se usa un equipo modesto, compuesto de reglas, escuadras, mesas para dibujar y piezas de papel o cartón (pocas veces se usan hojas metálicas) para hacer los moldes.

\section{Corte}

Para cortar la tela, se acomoda la misma en mesas tendedoras que son máquinas simples encargadas de estirar la tela. Sobre la tela extendida se dibujan y marcan los cortes a efectuar de acuerdo con los patrones. La tela marcada se coloca encima de 200 y hasta 300 piezas de tela tendida y entonces se usa una cortadora de cuchilla recta para cumplir la operación. Los trozos de tela resultantes se distribuyen posteriormente a las líneas de precosido, ojalado, botonado, etc. En algunas empresas se planchan determinadas partes antes de ensamblarlas. Esto no parece ser lo usual.

\section{Costura}

Esta fase de producción, se subdivide en varias tareas. Esta es la sección de la manufactura de ropa más amplia por el número de operarios y de máquinas que participan en la misma. Las tareas que componen esta fase no son las mismas para las diversas prendas de uso exterior, pero se pueden agrupar en 1) precosido de partes (como bolsas, presillas, cuellos, etc.), para lo cual se usan máquinas de coser "especiales", tales como las ribeteadoras, las presilladoras, las máquinas para cortar y voltear puños y cuellos, etc., 2) cosido de ojales y botones que requiere máquinas especializadas en tales operaciones; y 3) el ensamble de la prenda, para lo cual se pueden usar máquinas zig-zag, sencillas (es decir, planas, de costura recta) de una o más agujas, etc. Ha habido varios planteamientos de ingeniería industrial para ordenar las líneas de producción, pero se puede decir que lo más común es la disposición de series de máquinas en el siguiente orden:

1) máquinas para ribetear, para orlear y para cortar y voltear cuellos y puños;

2) máquinas para hacer ojales y para coser los ojales;

3) máquinas para pespuntear e hilvanar;

4) algunas otras máquinas especiales (como presilladoras, pegadoras de broches y cosedoras de elásticos);

5) máquinas para el ensamble de las diversas partes que componen la prenda; y

6) máquinas de coser botones.

\section{Inspección y acabado}

En esta parte de la producción, se efectúa una revisión de la manufactura de las prendas, generalmente una vez que las mismas están ensambladas y antes del planchado. En algunos casos, la inspección se lleva a cabo en 
las diversas secciones de la manufactura y se intensifica más en las fases de cosido y acabado. Posteriormente las prendas son limpiadas, despeluzadas y planchadas. Para el planchado se utilizan comúnmente planchas de vapor. También en esta fase se etiquetan las prendas y se doblan para su posterior empaque y despacho. 